\title{
THE CASE FOR LIBERAL SPECTRUM LICENSES: A Technical and Economic Perspective
}

\author{
Thomas W. Hazlett ${ }^{\dagger}$ \& Evan T. Leot
}

TABLE OF CONTENTS

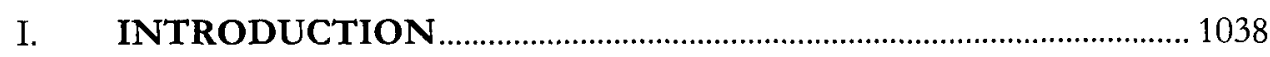

II. RIVAL SPECTRUM MODELS ……………………………………..... 1039

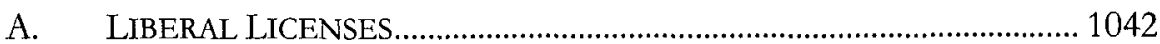

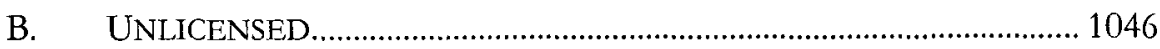

III. WI-FI, TELEVISION, AND WIDE-AREA WIRELESS .................... 1052

IV. WI-FI: THE STARBUCKS FALLACY …………………………….... 1055

A. BRoAdCASTING LICENSES: A BLAST FROM THE PAST ....................... 1062

V. WIRELESS CARRIERS AND LIBERAL LICENSES ......................... 1066

A. THE NEXTEL "REALLOCATION" ...................................................... 1066

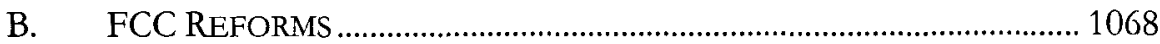

C. MARKETPLACE SPECTRUM ALLOCATION ………………………...... 1069

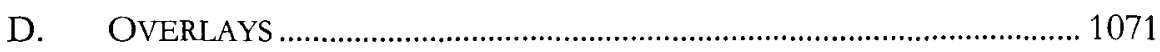

VI. FROM LMDS TO WIMAX, A REGULATORY ODYSSEY............... 1072

A. EARLY WMAN INVESTMENTS AND THE EMERGENCE OF FIXED WIRELESS TECHNOLOGIES ....................................................... 1073

B. CARRIERS ADVOCATE FOR WIMAX ……………………………….... 1076

C. FCC'S REgULATION VIA REGISTRATION HAS CREATED INEFFICIENCIES THAT LIBERAL LICENSES WOULD NOT ............... 1077

VII. THE QUIET PAST AND THE NOISY FUTURE …………………. 1079

(C) 2011 Thomas W. Hazlett and Evan T. Leo.

$\dagger$ Professor of Law \& Economics and Director, Information Economy Project, George Mason University. Professor Hazlett received his Ph.D. (Economics) from the University of California, Los Angeles; formerly held faculty positions at the University of California, Davis, Columbia University, and the Wharton School; and served as Chief Economist of the Federal Communications Commission.

H Partner, Kellogg, Huber, Hansen, Todd, Evans \& Figel, P.L.L.C. Mr. Leo received his J.D. from The George Washington University. The authors express their appreciation to Peter Huber and Charles Jackson for substantive technical comments and thank Mary Ann Endo for invaluable research assistance. All liability remains with the authors. 
A. CONFLICTS IN RADIO COMMUNICATIONS....................................... 1081

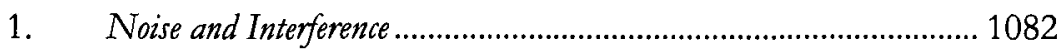

2. Pbysics and Architecture........................................................... 1085

3. Smart Radios, Dumb Crowds ....................................................... 1088

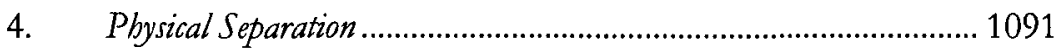

B. TECHNOLOGICAL INNOVATION AND MARKET EFFICIENCY........ 1095

VIII. CONCLUSION 1099

\section{INTRODUCTION}

The traditional system of radio spectrum allocation has inefficiently restricted wireless services. Alternatively, liberal licenses that cede de facto spectrum ownership rights yield incentives for operators to maximize airwave value. These authorizations have been widely used for mobile services in the United States and internationally, leading to the development of highly productive services and waves of innovation in technology, applications, and business models.

Serious challenges to the efficacy of such a spectrum regime have arisen, however. While the world marvels at the emergence of vast wireless networks, now serving over five billion global subscribers, ${ }^{1}$ many leading policy advocates in the United States have concluded that ceding de facto ownership of the airwaves through cellular licenses is a barrier to innovation and social progress. Advancing the examples of cordless phones, Wi-Fi, and Bluetooth, they credit unlicensed bandwidth-spectrum without exclusive ownership rights — as a Petri dish for disruptive technologies. These advocates extrapolate from examples to produce a template for restructuring the airwaves. Exclusive spectrum rights are obsolete, they claim; expanding "spectrum commons" would be more economically productive. Federal regulators have begun accepting this argument, shifting policies to favor allocations of unlicensed spectrum.

The marketplace, however, demonstrates that spectrum scarcity is alive and well. Costly conflicts over airwave use not only continue but have intensified with scientific advances that dramatically improve the functionality of wireless devices and so increase demand for spectrum access. These developments have increased the importance of social coordination in the use of wireless technologies by intensifying the competition between rival, mutually exclusive employments of frequencies. Alternative property

1. Mobile Broadband Subscriptions To Hit One Billion in 2011, INT'L TELECOMM. UNION (Feb. 7, 2011, 11:56 AM), http://www.itu.int/ITUD/ict/newslog/Mobile+Broadband+ Subscriptions+To+Hit+One+Billion+In+2011.aspx. 
rules are available to guide this coordination. Selecting rules that most reliably allow spectrum to generate the highest economic gains is socially efficient.

This Article evaluates the economic and technical arguments underlying this choice of regulatory regime. We first trace the path from traditional licenses, which systematically squandered valuable wireless opportunities, to reforms creating liberal licenses. Next, we examine the claim that advanced wireless technologies can effectively eliminate spectrum scarcity and, with it, the social utility of exclusionary rules for access to airwaves. We show that interference between radio signals is real and that conflicts between rival users are expensive. To productively use spectrum inputs for one set of applications or technologies constrains what such inputs can supply for alternatives. New and improved spectrum-sharing technologies do not eliminate these trade-offs but instead increase the value of communications, further exacerbating the competition for airspace. Overwhelming marketplace evidence demonstrates that liberal licenses promote beneficial social coordination, uniquely shifting spectrum to innovative uses, organizing investment in large-scale network infrastructure, and creating complex contracts permitting intensive spectrum sharing. Indeed, exclusive frequency rights are so broadly accommodating that they efficiently supply "spectrum commons," just as public parks are most productively provided within the context of private ownership of real estate.

\section{RIVAL SPECTRUM MODELS}

The U.S. mobile phone industry has achieved remarkable success. More than 302.9 million Americans-roughly ninety-six percent of the population-purchase wireless service. ${ }^{2}$ The nation's wireless carriers spend over $\$ 24$ billion a year ${ }^{3}$ building network infrastructure; about $\$ 22$ billion $^{4}$ more is spent on handsets and other wireless devices. U.S. companies like Qualcomm and Motorola have developed cutting-edge wireless technologies sold throughout the world. Firms like Apple, Palm, and Research in Motion (Blackberry) have assumed leading positions as device and application suppliers without owning wireless infrastructure by contracting with carriers

2. CTIA-The Wireless Ass'n ("CTIA"), Wireless Quick Facts (2010), http://www.ctia. org/media/industry_info/index.cfm/AID/10323. The term "wireless service" is used interchangeably with "mobile service," "cellular service," and "CMRS" (Commercial Mobile Radio Service, the FCC's official service designation) in this Article.

3. Id.

4. Consumer Elecs. Ass'n ("CEA"), CEA Historical Sales Data (2009) (on file with authors) [hereinafter CEA Database] (totaling 2009 retail cell phone sales ( $\$ 8.6$ billion) and smartphone sales ( $\$ 13.6$ billion)). 
who do. Application providers such as Yahoo!, Google, Twitter, and ESPN, while also lacking wireless assets, have likewise been able to reach mass market audiences through partnerships with wireless firms. The U.S. wireless industry as a whole generates $\$ 160$ billion in revenues per year ${ }^{5}$-more than broadcast and cable television combined. ${ }^{6}$ According to conservative estimates, the industry creates more than $\$ 150$ billion per year in additional consumer benefits. ${ }^{7}$

Radio spectrum is a key input to the wireless industry. Licenses issued by the Federal Communications Commission ("FCC") enable firms to supply services via designated airwaves; the nature of the spectrum rights the FCC grants affect the volume, quality, cost, and scope of services that can be provided to customers. Through 2008, mobile networks could access only about $194 \mathrm{MHz},{ }^{8}$ just seven percent of the prime bandwidth below $3 \mathrm{GHz}$ (the range most economically viable for broadcasting and mobile services, commonly considered "beachfront property")." In September 2006, Advanced Wireless Service ("AWS") licenses representing an additional 90 $\mathrm{MHz}$ of frequency space in the $1.7 \mathrm{GHz}$ and $2.1 \mathrm{GHz}$ bands were auctioned, with the U.S. Treasury collecting $\$ 13.7$ billion. ${ }^{10}$ These frequencies were

5. CTLA, supra note 2.

6. Compare CTIA, supra note 2, with Agata Kaczanowska, Television Broadcasting in the US, IBISWORLD, 3 (Feb. 2011), http://clients.ibisworld.com/industryus/default.aspx? indid $=1261$ (estimating that television broadcasting revenue totaled $\$ 36.1$ billion in 2010), and Nat'l Cable \& Telecomms. Ass'n, Industry Data, http://www.ncta.com/Statistics.aspx (last visited Sept. 2, 2011) (estimating cable revenue totaled $\$ 89.9$ billion in 2009).

7. Jerry A. Hausman, Cellular $3 G$ Broadband and $W i F i$, in FRONTIERS OF BROADBAND, Electronic AND MoBILE COMmerce 9, 11 (R. Cooper \& G. Madden eds., 2004); see also Roger Entner, Ovum, The Increasingly Important Impact of Wireless Broadband Technology and Services on the U.S. Economy, CTIA, 2 (2008), http://files.ctia.org/pdf/Final_OvumEconomic Impact_Report_5_21_08.pdf (estimating that by 2016 the wireless industry will help bring about $\$ 427$ billion per year in productivity gains, more than the productivity gains currently provided by the motor vehicle and pharmaceutical industries combined).

8. Rysavy Research, Mobile Broadband and Spectrum Demand 23 (2008), http://www.rysavy.com/Articles/2008_12_Rysavy_Spectrum_Demand_pdf. For a detailed description of mobile (and other) allocations under $3 \mathrm{GHz}$, see Evan Kwerel \& John Williams, A Proposal for a Rapid Transition to Market Allocation of Spectrum (Fed. Commc'ns Comm'n, Working Paper No. 38, 2002), available at http://wireless.fcc.gov/auctions/ conferences/combin2003/papers/masterevanjohn.pdf.

9. Om Malik, $700 \mathrm{MHz}$ Explained in 10 Steps, GIGA OM (Mar. 14, 2007, 6:30 AM), http://gigaom.com/2007/03/14/700mhz-explained/ ("Due to its broadcast-attractive physics (like its ability to penetrate walls), this spectrum is desirable for both broadband communications in general and public-safety uses in particular.").

10. Public Notice, Fed. Commc'ns Comm'n ("FCC"), Auction of Advanced Wireless Services Licenses Closes (Sept. 20, 2006), http://hraunfoss.fcc.gov/edocs_public/ attachmatch/DA-06-1882A1.pdf. Due to regulatory lags, AWS bandwidth was not generally available to licenses until well into 2007 or even 2008. There is also a lag between the time 
encumbered by a wide range of government users, were not generally available to licensees through $2008,{ }^{11}$ and are gradually being deployed. ${ }^{12}$ In March 2008, the FCC conducted further auctions for rights to use $52 \mathrm{MHz}$ in the $700 \mathrm{MHz}$ band, collecting another $\$ 18.958$ billion in winning bids. ${ }^{13}$ The $700 \mathrm{MHz}$ frequencies were occupied, in part, by analog TV broadcast stations that were switched off June 12, 2009 as part of the transition to digital television. ${ }^{14}$ These frequencies are being deployed in emerging Fourth Generation ("4G") wireless services, including Long Term Evolution ("LTE"), offering far higher data speeds and capacities than existing wireless broadband networks. ${ }^{15}$

licenses are assigned and networks are built. T-Mobile, the largest AWS bidder, first began serving customers using these frequencies in May 2008. See Katherine Noyes, T-Mobile's $3 G$ Network Touches Down in NYC, TECHNEwsWORLD (May 5, 2008), http://www.technews world.com/story $/ 62876$. html?wlc $=1235087208$.

11. See RYSAVY RESEARCH, supra note 8 , at 23 \& n. 48 .

12. Comments of T-Mobile USA, Inc. to the Nat'l Telecomms. and Info. Admin. at 12, Relocation of Federal Systems in the 1710-1755 Frequency Band, Review of the Initial Implementation of the Commercial Spectrum Enhancement Act, No. 0906231085-91085-01 (U.S. Dep't of Commerce Aug. 21, 2009), available at http://www.ntia.doc.gov/comments/ 2009/CSEA/T-Mobile_CSEA_NOI_Comments_8-21-09.pdf.

13. Auction 73: $700 \mathrm{MHz}$ Band, FED. COMMC'Ns COMM'N (Feb. 10, 2009), http://wireless.fcc.gov/auctions/default.htm?job=auction_summary\&id=73; Revised 700 MHz Band Plan for Commercial Services, FED. COMMC'NS COMM'N (Sept. 5, 2007), http://wireless.fcc.gov/auctions/data/bandplans/700MHzBandPlan.pdf.

14. In 1997 the FCC assigned each TV station a new digital TV broadcasting license, placing the digital stations on channels $2-51$ to allow the remaining channels assigned to TV broadcasting (52-69) to be later reallocated. By regulatory mandate, stations were broadcasting in digital formats on their new digital channel assignments by 2002 . The end of analog broadcasting on TV Channels 52-69 had been mandated by Congress to occur December 31, 2006, but the mandate contained conditions unlikely to be met in the vast majority of markets. Long delays were anticipated. Hence, in the Digital Transition and Public Safety Act of 2005, Congress set February 17, 2009 as the new analog switch-off date. Just days before the deadline, however, Congress, responding to a request from the new Obama administration, voted to delay the switch-off until June 12, 2009. This deadline held. Ending analog TV broadcasting on channels 52-69 made $108 \mathrm{MHz}(6 \mathrm{MHz}$ per channel) available for reallocation. Some $70 \mathrm{MHz}$ of this "digital dividend" was allocated to liberal licenses auctioned by the FCC in 2002, 2003, and 2008. For an analysis of how the analog switchover to digital television worked, see Matthew Lasar, $A$ Year of Digital TV: Who Won the Transition?, ARS TECHNICA June 15, 2010, 8:45 AM), http://arstechnica.com/telecom/ news/2010/06/a-year-of-digital-tv-who-won-the-transition.ars.

15. See Marguerite Reardon, The 411 on ATd'T's 4G Strategy (FAQ), CNET NEws (Dec. 21, 2010, 4:00 AM), http://news.cnet.com/8301-30686_3-20026253-266.html ("Currently, AT\&T is using $700 \mathrm{MHz}$ spectrum holdings as well as spectrum it acquired in the FCC's Advanced Wireless Services spectrum auction."); Maravedis, Verizon vs. Clearwire: A $4 G$ Comparison, LTE WORLD (Dec. 8, 2010), http://lteworld.org/blog/verizon-vs-clearwire- 4gcomparison (stating that Verizon's "LTE network will be [deployed using] . . its spectrum resources of $34 \mathrm{MHz}$ in the $700 \mathrm{MHz}$ band'). 


\section{A. LiBERAL LICENSES}

Much of the case for unlicensing spectrum begins with the argument that broadcast television wastes valuable radio spectrum and that an unlicensed regime can make more productive use of frequencies. ${ }^{16}$ For empirical support, commons advocates rely heavily on the success of $\mathrm{Wi}-\mathrm{Fi}$, which is now widely used in local area networks, public hot spots, and other applications. Wi-Fi, as one commons advocate explains, is "the most prominent unlicensed wireless technology available today" and "a great case study for the impact of dynamic wireless technologies." 17 Introduced in the late $1990 \mathrm{~s},{ }^{18} \mathrm{Wi}-\mathrm{Fi}$ radios now provide high-speed, digital connections to millions of users using unlicensed bandwidth.

TV broadcasters, by contrast, provide video service via exclusive licenses. But TV band airwaves are dramatically under-utilized, littered with "white spaces" where little to no communications travel. Indeed, all over-theair TV reception could be transferred to cable and/or satellite TV systems at a small fraction of the cost of the TV airwaves that would be released for more valuable services. ${ }^{19}$ Thus, exclusive spectrum rights impede innovation and promote inefficient use of the airwaves.

Both ends of the comparison are confused. Broadcast TV licenses are locked into inefficient market structures precisely because of "command and control" regulation that economists have long condemned as "Gosplan.",20

16. Paul Baran, Symposium Paper, Is the UHF Frequency Shortage a Self Made Problem? (Marconi Centennial Symposium, Bologna, Italy, June 23, 1995), available at http://www.interesting-people.org/archives/interesting-people/199507/msg00023.html.

17. KeVin Werbach, Radio Revolution: The Coming Age of UnLiCEnsed WIRELESS 22 (2003), available at http://werbach.com/docs/RadioRevolution.pdf; see also Fed. Commc'ns Comm'n, Connected \& On the Go: Broadband Goes Wireless 5 (Feb. 2005), available at http://hraunfoss.fcc.gov/edocs_public/attachmatch/DOC-256693A1.pdf [hereinafter FCC Task Force Paper] (noting the tremendous success of Wi-Fi devices); Yochai Benkler, Some Economics of Wireless Communications, 16 HARV. J.L. \& TECH. 25, 30 (2002) (noting the "breathtaking growth" of Wi-Fi devices that "rely on utilizing frequencies that no one controls").

18. See generally Kevin Negus \& Al Petrick, History of Wireless Local Area Networks (WLANs) in the Unlicensed Bands, 11 INFO, no. 5, 2009, at 35.

19. Richard H. Thaler, The Buried Treasure in Your TV Dial, N.Y. TiMES, Feb. 28, 2010, at BU7; Thomas W. Hazlett, The U.S. Digital TV Transition: Time To Toss the Negroponte Switch (AEI-Brookings Joint Ctr. for Regulatory Studies, Working Paper No. 01-15, 2001) [hereinafter Hazlett, U.S. Digital TV Transition]; Thomas W. Hazlett, Transition to Yesterday: Subsidizing the Killer App of 1952, ARS TECHNICA (Nov. 3, 2008, 10:40 PM), http://arstechnica.com/old/content/2008/11/dtv-transition-to-yesterday.ars [hereinafter Hazlett, Transition to Yesterday].

20. Gerald R. Faulhaber \& David J. Farber, Spectrum Management: Property Rights, Markets, and the Commons 6 (AEI-Brookings Joint Ctr. for Regulatory Studies, Working Paper No. 02- 
Ronald H. Coase's classic critique of the FCC focused on these licenses, leading him to recommend adoption of private property rights in spectrum to replace "public interest" assignments by regulators. ${ }^{21}$ Coase's proposal was considered radical. When Coase explained his proposal at a 1959 FCC hearing, the first question a Commissioner posed was, "Is this all a big joke?"22

It was not. Were licensees able to freely control the spectrum allocated to their licenses, rather than being granted narrow rights to transmit in ways regulators specified, these de facto property owners would have naturally sought to expand value creation--to make productive use of "white spaces." It took a quarter century for regulators to start (implicitly) embracing Coase's proposal. Beginning with licensing of cellular phone service in the 1980s, carriers were given far more control over the use of their spectrum as compared to radio and TV broadcasting licensees. ${ }^{23}$

Why the shift? For one thing, the political interest in regulating cellular was lower because the content transmitted over cellular networks is private, whereas broadcasting is inherently public, transmitting content influencing social, cultural, and political developments. For another thing, the cost of regulating cellular was much higher. Instead of a single, one-way transmitter, cellular systems involve the integration of thousands of base stations and millions of handsets, each a receiver and a transmitter moving in space. The increasingly liberal licenses granted to mobile phone operators have enabled firms to design their own services, adapt new technologies, determine network architectures, and experiment with new business models as profit criteria dictate-a radical departure (for allocated spectrum) ${ }^{24}$ from the traditional broadcast license.

The historical broadcast license is quite distinct from a liberal license. Broadcast licensees are endowed with extremely delimited property rights in spectrum; their specific use permits authorize only a broadcasting service operated according to fixed technical standards and pre-specified service definitions. Licensees cannot allocate the spectrum allocated to their licenses

12, 2002). The term references bureaucratic management techniques for industrial markets in the Soviet Union. Id. at 6.

21. Ronald H. Coase, The Federal Communications Commission, 2 J.L. \& ECON. 1 (1959).

22. Ronald H. Coase, Comment on Thomas W. Haqlett, 41 J.L. \& ECON. 577,579 (1998).

23. Thomas W. Hazlett \& Matthew L. Spitzer, Advanced Wireless Technologies and Public Policy, 79 S. CAL. L. REv. 595, 623-31 (2006).

24. The reforms begun with cellular licensing did not constitute full liberalization in that only modest amounts of bandwidth had been allotted to liberal licenses. More widespread reforms have occurred in other countries. See Thomas W. Hazlett, Property Rigbts and Wireless License Values, 51 J.L. \& ECON. 563 (2008). 
to higher valued uses, even if alternatives are more profitable. The gross inefficiencies that result are not due to licensing, but to truncating private ownership of spectrum rights. As Coase recognized, granting licensees ownership of spectrum, as in broad, "flexible use" permits, ${ }^{25}$ allows market forces to divert spectrum resources to their most socially valuable employments. ${ }^{26}$

These market forces can be seen at work in recent FCC sales of new wireless licenses. These sales will bring the total amount of licensed spectrum available to mobile carriers in the United States up to levels comparable to those in the European Union. By 2001, EU regulators had issued mobile licenses allocating an average of about $266 \mathrm{MHz}$ per country, about fifty percent higher than the amount then allocated in the United States. ${ }^{27}$ The recent AWS and $700 \mathrm{MHz}$ auctions bring the U.S. total up to about 360 $\mathrm{MHz}$ available for mobile service, ${ }^{28}$ but EU countries are now preparing to

25. Kwerel \& Williams, supra note 8 , at 3-4 (using the term "flexible use" as a proxy for exclusive spectrum rights). Hazlett and Spitzer expand the term to EAFUS: "exclusivelyassigned, flexible-use spectrum." Hazlett \& Spitzer, supra note 23, at 623.

26. With colleagues, Coase outlined a detailed policy proposal for private property rights in spectrum in 1962, a considerable feat given the relative dearth of market data to rely on. See Ronald Coase, William H. Meckling \& Jora Minasian, Problems of Radio Frequency Allocation (Sept. 1995) (unpublished manuscript originally written in 1963), available at http://www.rand.org/pubs/drafts/2008/DRU1219.pdf. The efficiency of the approach suggested has, indeed, proven successful as per many economic analyses. Perhaps the most influential source is the 2002 report on spectrum policy commissioned by the government of the United Kingdom. MARTIN CAVE, REVIEW OF RADIO SPECTRUM MANAGEMENT (2002), available at http://www.ofcom.org.uk/static/archive/ra/spectrum-review/2002review/1_ whole_job.pdf.

27. Thomas W. Hazlett \& Roberto E. Muñoz, Spectrum Allocation in Latin America: An Economic Analysis, 21 INFO. ECON. \& POL'Y 261, 262 (2009). Note that the smaller U.S. allocations cannot be explained by cross-country size or cost disparities. A reduction in available bandwidth means that, in any given market, wireless operators have less capacity, and slower average speeds, to accommodate a given number of customers, all else (including network infrastructure investments) equal.

28. See Blair Levin et al., What $700 \mathrm{MHz}$ Winners Can Do with Their Spectrum 4 (Apr. 15,2008 ) (unpublished manuscript) (on file with authors). These totals do not include spectrum to "fixed" broadband services, such as the $3.5 \mathrm{GHz}$ band in Europe, and the 2.5 $\mathrm{GHz}$ band in the United States. While these wireless services are being adapted for mobile use, the migration-undoubtedly promising as a future source of competition-is yet nascent. Clearwire is developing a nationwide wireless broadband network using WiMax technology delivered over $2.5 \mathrm{GHz}$ frequencies. There is potentially some $190 \mathrm{MHz}$ available for use there, divided between EBS (Educational Broadband Services) licenses held by nonprofit (mostly educational) institutions and BRS (Broadband Radio Service) licenses held by commercial operators. Transaction costs associated with re-aggregating the dispersed, truncated, and conflicting transmission rights have been formidable. See Thomas W. Hazlett, Spectrum Tragedies, 22 YALE J. ON REG. 242, 258 (2005). As of year-end 2010, Clearwire reported 4.4 million U.S. subscribers. Dan Meyer, Clearwire Posts Strang Q4 Wholesale Growth, 
make major new allocations that will extend the advantage. ${ }^{29}$ To meet the perceived U.S. deficit, the FCC has announced that it "recommends making $500 \mathrm{MHz}$ of spectrum newly available for broadband by 2020 , with a benchmark of making $300 \mathrm{MHz}$ available by 2015." 30 The goal is ambitious; previous experience suggests that even much smaller allocations take much longer to implement. ${ }^{31}$

The FCC issued cellular licenses in the United States between 1982 and 1989, with Personal Communications Services ("PCS") license awards beginning in $1995 .^{32}$ These authorizations represented a paradigm shift in the regulation of spectrum use, rejecting the traditional regime crafted for and typified by broadcasting licenses. For radio and television stations, licensees receive narrowly crafted operating permits that define the services they can provide, the technology they may employ, the physical locations where they must place transmitters, transmitter height, and the business model (advertising-based, non-subscription) they must use. A TV broadcaster cannot, for example, forgo video transmissions and instead use its licensed spectrum to provide high-speed internet service.

Cost Conservation Remains Intact, RCR WIRELESS NEws (Feb. 17, 2011, 7:08 PM), http://www. rcrwireless.com/article/20110217/CARRIERS/110219933/1097.

29. Comments of CTIA-The Wireless Association, In the Matter of Implementation of Section 6002(b) of the Omnibus Budget Reconciliation Act of 1993, WT Docket No. 0966, at 82-83 (Fed. Commc'ns Comm'n Sept. 30, 2009) ("Ofcom, the regulator in United Kingdom, is in the process of reallocating $355 \mathrm{MHz}$ of spectrum for commercial wireless services, which would bring the U.K.'s total up to $710 \mathrm{MHz}$.... Similarly, in Germany, 340 $\mathrm{MHz}$ of spectrum has been identified for reallocation, which will bring the total up to 645 $\mathrm{MHz} \ldots . .$, .

30. FED. COMMC'NS COMM'N, CONNECTING AMERICA: THE NATIONAL BROADBAND PLAN 26 (2010), available at http://download.broadband.gov/plan/national-broadband-planchapter-2-goals-for-high-performance-america.pdf.

31. See id. at 79. The six- to thirteen-year lags estimated by the FCC are conservative. For instance, the estimated length of the original cellular allocation was given to be eleven years. In fact, AT\&T first petitioned the FCC for cellular airwaves in 1958. Tom Farley, The Cell-Phone Revolution, 22 AM. HeRITAGE INVENTION \& TECH. 23 (2007). Yet, cellular licenses were not distributed until lotteries held between 1984 and 1989 were completed. Thomas W. Hazlett \& Robert J. Michaels, The Cost of Rent Seeking: Evidence from the Cellular Telepbone License Lotteries, 59 S. ECON. J. 425 (1993). Hence, the actual regulatory lag may well have been closer to thirty years than to the National Broadband Plan's estimate of eleven.

32. Thomas W. Hazlett, Assigning Property Rights to Radio Spectrum Users: Wby Did FCC License Auctions Take 67 Years?, 41 J.L. \& ECON. 529, 532, 535 (1998). Note that while the United States was the first country to widely assign cellular licenses (for analog voice services), EU countries issued 2G (Second Generation) licenses (for digital voice services) between 1989 and 1992. See LAURENT BENZONI \& Eva KALMAN, THE ECONOMICS OF RADIO FREQUENCY ALLOCATION (1993). This was years ahead of the comparable U.S. allocation for PCS, which began assigning licenses in 1995. See Peter Cramton, Evan Kwerel \& John Williams, Efficient Relocation of Spectrum Incumbents, 41 J.L. \& ECON. 647, 661 (1998). 
Wireless phone licenses-and particularly PCS licenses-were the first major implementation of two fundamental policy innovations: (1) awarding licenses by competitive bidding, thus abandoning assignments by regulatory fiat or lottery; ${ }^{33}$ and (2) permitting licensees wide discretion in using allotted frequency space. ${ }^{34}$ Auctions were efficiency enhancing, ${ }^{35}$ but the latter policy was of much greater significance for consumer welfare. ${ }^{36}$ With licensees free to choose services, technologies, architectures, and business models, market forces could, for the first time, optimize radio spectrum use. The emergence of vigorous economic activity, including high levels of network investment, led regulators to adopt liberal licenses as the new standard for wireless services.

\section{B. UNLICENSED}

In parallel to the evolution of the liberal license model, a second distinct FCC policy regime was developing. Traditionally, the FCC set aside bands for "unlicensed" use by low power, short-range radios-remote controls, short-range security systems, and baby monitors, for example. The FCC has also allocated such unlicensed bands for the use of non-communications devices, like microwave ovens and medical or scientific equipment that emit radiation, which potentially conflicts with the use of communications systems. The first unlicensed bands were established in 1938. ${ }^{37}$ In 1985, however, the FCC took a decisive step in authorizing a whole class of new unlicensed devices, thus eliminating the process of regulatory pre-approval under vague "public interest" criteria. This deregulatory initiative, which

33. License auctions were first authorized in Section 6002 of the Omnibus Budget Reconciliation Act of 1993, Pub. L. No. 103-66, \$ 6002, 107 Stat. 312, 387-97. The first spectrum auctions were for PCS awards. Lotteries had been used to assign cellular licenses. See generally JAMES B. MURRAY, JR., WiRELESS NATION (2001).

34. For example, cellular licenses were originally issued with a mandate that operators use the specific analog transmission format AMPS; there was no mandated format for digital PCS licenses.

35. Peter Cramton, Spectrum Auctions, in 2 Handbook of Telecommunications ECONOMTCS 605, 607 (Sumit Majumdar et al. eds., 2002).

36. See Thomas W. Hazlett \& Roberto E. Muñoz, $A$ Welfare Analysis of Spectrum Allocation Policies, 40 RAND J. ECON. 424, 437-38 (2009).

37. See Kenneth R. Carter, Ahmed Lahjouji \& Neal McNeil, Unlicensed and Unshackled: A Joint OSP-OET White Paper on Unlicensed Devices and Their Regulatory Issues 6 (Fed. Commc'ns Comm'n, OSP Working Paper No. 39, 2003), available at http://hraunfoss.fcc.gov/ edocs_public/attachmatch/DOC-234741A1.pdf. Amateur bands, including CB (citizens' band) frequencies, are organized on a similar basis to unlicensed bands, although radio operators are technically required to be licensed by the FCC. The requirement is loosely enforced. Moreover, licenses help to assure that users comply with FCC rules and do not cede control of spectrum space. In this sense, unlicensed (amateur) bands have been in use since before the Radio Act of 1927. 
began under President Jimmy Carter's FCC and was implemented under President Ronald Reagan's, aimed to reduce barriers to entry for new technologies. ${ }^{38}$ In place of a case-by-case regulatory process, the FCC set forth technical criteria, including power limits, to which new "Part 15" unlicensed devices would need to adhere. ${ }^{39}$ This policy paved the way for widespread use of unlicensed devices in the so-called Industrial, Scientific, and Medical ("ISM") frequencies in the $900 \mathrm{MHz}$ band (26 MHz), the 2.4 $\mathrm{GHz}$ band $(83.5 \mathrm{MHz})$, and at $5.8 \mathrm{GHz}(125 \mathrm{MHz})$. In subsequent years, the market introduced thousands of unlicensed devices under the "Part 15" framework, including cordless phones and Wi-Fi radios connecting computers in local area networks. ${ }^{40}$ One of the lead FCC engineers who worked on the regulatory initiative recounts that such devices were neither planned nor anticipated. ${ }^{41}$

In recent years, the FCC has moved aggressively to allocate more bandwidth to unlicensed (or "license-exempt") spectrum. ${ }^{42}$ In 1985, there

38. See Kenneth R. Carter, Unlicensed to Kill: A Brief History of the Part 15 Rules, 11 INFO, no. 5, 2009, at 8; Michael J. Marcus, Wi-Fi and Bluetooth: The Path from Carter and Reagan-Era Faith in Deregulation to Widespread Products Impacting Our World, 11 INFO, no. 5, 2009, at 19; Negus \& Petrick, supra note 18.

39. See 47 C.F.R. $\iint 15.1-.717$ (2010). In addition to the limiting technical constraints, Part 15 requires that an operator accept whatever interference is received and correct whatever interference is caused. Should harmful interference occur, the operator is required immediately to correct the interference problem, even if correction of the problem requires ceasing operation of the Part 15 system causing the interference. See Revision of Part 15 of the Commission's Rules Regarding Ultra-Wideband Transmission Systems (Revision of Part 15), 17 FCC Rcd. 7435, ๆ 6 n.2 (2002).

40. Devices are regulated under three methods at the FCC: verification, declaration of conformity, and certification. The latter category relies largely on tests performed by private firms. See Equipment Authorization (EA), FED. COMMC'NS COMM'N, http://www.fcc.gov/ oet/ea/procedures.html\#sec1 (last visited Jan. 21, 2011).

41. Marcus, supra note 38, at 29-30 ("In the 1981-85 period when these rules were drafted, wireless LANs were not a common topic of discussion. Indeed, Ethernet and other LAN installations were rare outside technical organizations and unheard of in homes. The deliberations had raised the possibility of 'wireless data terminals' as an example, but did not specifically 'tilt' in favor of this application in the resulting rules. The Carter and Reagan era faith in deregulation laid the foundation for the future development of a variety of products without the need for government action.").

42. The rationale for this policy shift was laid out in the FCC's Spectrum Policy Task Force Report issued in November 2002 and was strongly endorsed by then FCC Chair Michael Powell, appointed by President George W. Bush. See Spectrum Policy Task Force, FCC Report, ET Docket No. 02-135 (Nov. 2002); see also Lawrence Lessig, Technology over Ideology, WIRED (Dec. 2004), available at http://www.wired.com/wired/archive/12.12/ view.html?pg=5 ("When Powell took charge, most thought the FCC would quickly launch massive spectrum auctions. The reigning ideology was that spectrum is land, and that markets allocate land most efficiently. But Powell's FCC quickly sabotaged this idea. ... Auctions were slowed; spectrum commons were encouraged."). 
was $234.5 \mathrm{MHz}$ of spectrum in the ISM bands available to unlicensed devices. ${ }^{43}$ By 2004, the FCC had allocated approximately $665 \mathrm{MHz}$ of spectrum in the same frequency range to unlicensed use. In comparison, as of that same date, about $385 \mathrm{MHz}$ in this range had been allocated to liberal licenses-an unlicensed-to-licensed ratio of $1.7^{44}$ This tends to be substantially higher than in other countries, where the ratio is generally less than one. ${ }^{45}$

The U.S. government push favoring unlicensed bandwidth was further seen in an important 2005 decision. Regulators allocated a band of $50 \mathrm{MHz}$ (3.65 $\mathrm{GHz}$ to $3.70 \mathrm{GHz}$ ) for terrestrial services including WiMax, an emergent wireless broadband technology often referred to as "wi-fi on steroids." ${ }^{46}$ Despite the general use of neighboring frequencies (known generically as "the $3.5 \mathrm{GHz}$ band") in international markets as licensed spectrum, and the development of WiMax radios using these airwaves by equipment makers, the FCC chose to allocate the entire band for unlicensed (non-exclusive) access. ${ }^{47}$ This generated controversy even among the major vendors of radios for use in unlicensed spectrum, Intel and Alvarion, which had opposed the FCC's approach. ${ }^{48}$ Then, in December 2008, in a much larger and more valuable band where the Commission sought to choose between licensed and unlicensed models, the FCC ruled that the frequencies previously set aside for TV broadcasts would be opened for the use of unlicensed devices. ${ }^{49}$ This decision made available up to an additional 240

43. In 2002, the requirement that devices using ISM bands conform to spread spectrum formats was abolished, while power limits and other technical constraints were retained. Amendment of Part 15 of the Commission's Rules Regarding Spread Spectrum Devices, 17 FCC Rcd. 10,755 (2002).

44. See also Hazlett, supra note 28 , at tbl.2 (comparing $648.5 \mathrm{MHz}$ of unlicensed spectrum to $189 \mathrm{MHz}$ of "flexible use" licensed spectrum).

45. See infra Figure 1.

46. See, e.g., George Ou, White Space Backbauls-A Penny Wise and a Pound Foolish, DigITAL SOC’Y (Mar. 16, 2010), http://www.digitalsociety.org/2010/03/white-spacebackhauls-a-penny-wise-and-a-pound-foolish.

47. Wireless Operations in the $3650-3700 \mathrm{MHz}$ Band; Rules for Wireless Broadband Services in the $3650-3700 \mathrm{MHz}$ Band; Additional Spectrum for Unlicensed Devices Below $900 \mathrm{MHz}$ and in the $3 \mathrm{GHz}$ Band; Amendment of the Commission's Rules with Regard to the $3650-3700 \mathrm{MHz}$ Government Transfer Band (Wireless Operations in the $3650-3700 \mathrm{MHz}$ Band), 20 FCC Rcd. 6502, ๆ 25 (2005).

48. See Jerry Brito, The Spectrum Commons in Theory and Practice, 2007 STAN. TECH. L. REV. 1 , ๆึ $52,87$.

49. Unlicensed Operation in the TV Broadcast Bands; Additional Spectrum for Unlicensed Devices Below $900 \mathrm{MHz}$ and in the $3 \mathrm{GHz}$ Band (Unlicensed Operation in the TV Broadcast Bands), 23 FCC Rcd. 16,807 (2008); see also Unlicensed Operation in the TV Broadcast Bands, 25 FCC Rcd. 18,661 (2010). 
$\mathrm{MHz}$ of bandwidth in the median U.S. market ${ }^{50}$ and brought the total unlicensed allocation to $955 \mathrm{MHz} .^{51}$ By comparison, as of year-end 2008, approximately $422 \mathrm{MHz}$ had been allocated to liberal licenses, bringing the ratio of unlicensed to liberal-license spectrum to about $2.3: 1 .^{52}$

50. Under FCC rules, unlicensed devices will be permitted to access TV band spectrum not occupied by TV broadcasters. The average TV market features 8.6 stations (there are 1800 full-power stations and 210 TV markets), and each market is allocated forty-nine TV channels, allocated $6 \mathrm{MHz}$ each $(294 \mathrm{MHz}$ total). This leaves about $240 \mathrm{MHz}$ for unlicensed use. We note that the bandwidth that would actually be available for unlicensed devices is much below the $240 \mathrm{MHz}$ set aside. See Michael Calabrese, Broadcast to Broadband: Unlicensed Access to Unused TV Channels, IEEE INTERNET COMPUTING, 71 (Apr. 2008), http://www. newamerica.net/files/Broadcast_to_Broadband.pdf. That is because the FCC usage restrictions, ostensibly employed to protect over-the-air TV viewers on the one side and unlicensed device users on the other, leave many unused channels in place to separate rival applications. Comments of Charles L. Jackson \& Dorothy Robyn at i, Unlicensed Operation in the TV Broadcast Bands, ET Docket Nos. 04 -186/02-380 (Fed. Commc'ns Comm'n Jan. 31, 2007).

51. This total includes $28 \mathrm{MHz}$ in the $900 \mathrm{MHz}$ band and $83.5 \mathrm{MHz}$ in the $2.4 \mathrm{GHz}$ band. Carter, Lahjouji \& McNeil, supra note 37, at 7. It also includes $50 \mathrm{MHz}$ in the $3.7 \mathrm{GHz}$ band. See Wireless Operations in the 3650-3700 MHz Band, 20 FCC Rcd. 6502, I 1. In addition, there is a total of $555 \mathrm{MHz}$ of unlicensed allocation in the $5 \mathrm{GHz}$ band. See Revision of Parts 2 and 15 of the Commission's Rules to Permit Unlicensed National Information Infrastructure (U-NII) Devices in the $5 \mathrm{GHz}$ Band (Revision of Parts 2 and 15), 18 FCC Rcd. 24,484 , IT 4-5 (2003). There is then another $240 \mathrm{MHz}$ in the "white spaces" TV band discussed immediately above. See discussion supra note 50.

52. By year-end 2008 , some $422 \mathrm{MHz}$ of spectrum was allocated for liberal licenses, although much of it was encumbered. In particular, much of the capacity of $700 \mathrm{MHz}$ licenses was blocked by TV broadcasts ongoing until the June 2009 analog switch-off. Licensed spectrum allocations are calculated as: $50 \mathrm{MHz}(800 \mathrm{MHz}$ cellular), $120 \mathrm{MHz}(1.9$ $\mathrm{GHz}$ PCS), $14 \mathrm{MHz}$ (SMR, 1.9 GHz), $90 \mathrm{MHz}(1.7 / 2.1 \mathrm{GHz}$ AWS), $70 \mathrm{MHz}$ (700 MHz), 78 $\mathrm{MHz}(2.5 \mathrm{GHz}, 136-\mathrm{MHz}$ BRS channels). The $30 \mathrm{MHz}$ of WCS spectrum is not included because, while license rules are liberal in terms of services and technologies, emission rules are exceedingly stringent. The WCS licenses, auctioned in 1997, attracted extremely low bids as a result. See Cramton, supra note 35, at 635 . Ironically, the FCC blocked a 2006 bid by satellite radio licensee XM to buy WCS licenses. With Satellite Digital Audio Radio Service licenses allocated spectrum adjacent to the WCS band, integration of ownership could have easily solved the externality problem. See Tony Sanders, FCC Delay Scotches WCS Merger, RADIO MONITOR (May 22, 2006), available at http://www.allbusiness.com/services/motionpictures /4479825-1.html. On how ownership structures impact transaction costs, see Harold Demsetz, Ownership and the Externality Problem, in PROPERTY RIGHTS: COOPERATION, CONFLICT, AND LAW 282 (T.L. Anderson \& F.S. McChesney eds., 2003). 
Figure 1: Ratios of Unlicensed-to-Licensed Spectrum Under 6 GHz (2005)

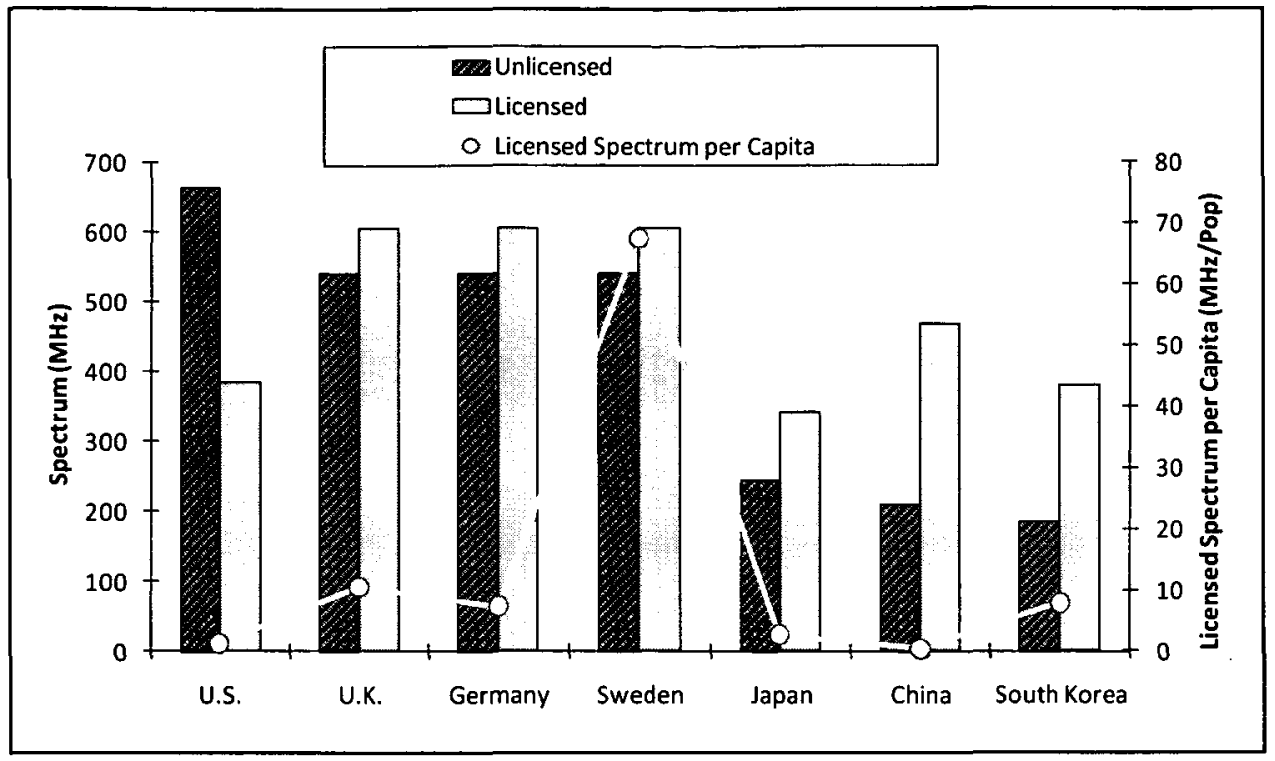

An influential coalition composed of major technology firms such as Intel, ${ }^{53}$ Microsoft, ${ }^{54}$ Apple, ${ }^{55}$ Cisco, ${ }^{56}$ and Google, ${ }^{57}$ together with computer manufacturers and several academics, ${ }^{58}$ has been urging the FCC to expand the unlicensed "spectrum commons." Advanced low-power radios, they argue, can use embedded sensors and digital intelligence to sense each other's

53. See, e.g., P. Pitsch, The Future of Radio Spectrum Policy, Technology@Intel MaG., Mar. 2004.

54. See, e.g., Comments of Microsoft Corp. at 2-3, Revision of Parts 2 and 15, ET Docket No. 03-122 (Fed. Commc'ns Comm'n Sept. 3, 2003).

55. See, e.g., Comments of Wireless Info. Networks Forum, Apple Computer, Inc. Petition for Rulemaking To Allocate Spectrum in the $5 \mathrm{GHz}$ Band To Establish a Wireless Component of the National Information Infrastructure, RM-8653 (Fed. Commc'ns Comm'n July 10, 1995).

56. See, e.g., Wireless and Spectrum Management, CISCO SYs. Jan. 2005), http://www.cisco. $\mathrm{com} / \mathrm{web} /$ about/gov/networks/wireless_spectrum_management.html.

57. See, e.g., Stephanie Condon, Google Launches Free the Airnvaves, CNET NEws (Aug. 18, 2008, 7:38 AM), http://news.cnet.com/8301-1035_3-10018917-94.html.

58. See, e.g., LAWRENCE Lessig, THE Future OF IdEAS: THE FATE OF THE COMMONS IN A CONNECTED WORLD 73-84 (2001); WERBACH, supra note 17, at 47; Yochai Benkler, Overcoming Agoraphobia: Building the Commons of the Digitally Networked Environment, 11 HARV. J.L. \& TECH. 287 (1998) [hereinafter Benkler, Overcoming Agorapbobia]; Benkler, supra note 17; Kevin Werbach, Supercommons: Toward a Unified Theory of Wireless Communication, 82 TEX. L. REV. 863 (2004); J.H. Snider, Reclaiming the Vast Wasteland: The Economic Case for Re-allocating to Unlicensed Service the Unused Spectrum (White Space) Between TV Channels 2 and 51 (New Am. Found. Working Paper, 2006), available at http://www.newamerica.net/publications/ policy/the_economic_case_for_re_allocating_the_unused_spectrum_white_space_between _tv_channels_2_and_51_to_unlicense. 
presence and avoid interfering with each other's transmissions. In the most aggressive form of the argument, all carriers and consumers should therefore be allowed to transmit radio signals in any frequency band using one of these smart radios.

With this technology, these advocates claim, exclusive, property-like rights in spectrum are obstructive anachronisms. The FCC should therefore designate more frequency bands as unlicensed-i.e., to be used only by FCCpermitted, low-power radios. And the FCC should allow anyone to operate low-power transmitters in licensed bands allocated for broadcasting services, wireless phone companies, and others, so long as these "underlay" devices operate below some power threshold set by the FCC and incorporate smart protocols to avoid interfering with licensed transmissions. ${ }^{59}$

The FCC has been receptive to this vision. In 2002, an FCC-convened task force advocated further use of unlicensed bands. ${ }^{60}$ On the predicate that unlicensed bands have been a "tremendous success," the Commission designated several new bands for unlicensed access. ${ }^{62}$ The FCC also authorized underlay rights for ultra-wideband ("UWB") radios in bands above $10 \mathrm{GHz}$, provided they use very low power to leave other communication signals undisturbed. ${ }^{63}$ The FCC further considered authorizing unlicensed devices to access licensed spectrum in its "Interference Temperature" proceeding, launched in November 2003; the initiative failed, however, and the proceeding was terminated in May $2007 .{ }^{64}$ And the "3650 MHz" and "TV Band White Spaces" proceedings, mentioned supra, were clear victories for champions of unlicensed spectrum access who

59. See sources cited supra note 58.

60. See Fed. COMmC'NS COMM'N, REPORT OF THE SPECTRUM EFFICIENCY WORKING GROUP (2002), available at http://www.fcc.gov/sptf/files/SEWGFinalReport_1.pdf.

61. Notice of Inquiry, Additional Spectrum for Unlicensed Devices Below $900 \mathrm{MHz}$ and in the $3 \mathrm{GHz}$ Band (900 MHz and $3 \mathrm{GHz}$ ), 17 FCC Rcd. 25,632, \ 6 (2002).

62. This includes $2 \mathrm{GHz}$ in the $57-59 \mathrm{GHz}$ band (2000); $255 \mathrm{MHz}$ in the $5.470-5.725$ $\mathrm{GHz}$ band; $2.9 \mathrm{GHz}$ in the $92.0-94.0$ and $94.1-95.0 \mathrm{GHz}$ bands (2003); and $50 \mathrm{MHz}$ in the 3.65-3.7 GHz band (2005). Amendment of Part 2 of the Commission's Rules To Allocate Additional Spectrum to the Inter-Satellite, Fixed, and Mobile Services and To Permit Unlicensed Devices To Use Certain Segments in the $50.2-50.4 \mathrm{GHz}$ and $51.4-71.0 \mathrm{GHz}$ Bands, 15 FCC Rcd. 25,264, ๆ 2 (2000); Revision of Parts 2 and 15, 18 FCC Rcd. 24,484 (2003); Allocations and Service Rules for the 71-76 GHz, 81-86 GHz and 92-95 GHz Bands, 18 FCC Rcd. 23,318, II 4 (2003); Wireless Operations in the 3650-3700 MHz Band, 20 FCC Rcd. 6502 (2005).

63. Revision of Part 15, 17 FCC Rcd. 7435, \19 (2002).

64. Establishment of an Interference Temperature Metric To Quantify and Manage Interference and To Expand Available Unlicensed Operation in Certain Fixed, Mobile and Satellite Frequency Bands (Interference Temperature Metric), 22 FCC Red. 8938, $\uparrow 3$ (2007). 
prevailed in head-to-head match-ups where the Commission considered whether to apply licensed or unlicensed rules for specific frequencies.

\section{WI-FI, TELEVISION, AND WIDE-AREA WIRELESS}

Commons advocates misread the market evidence on Wi-Fi. Although highly effective and popular as a method for connecting PCs to broadband networks, fixed, short-range data links create wireless local area networks ("WLANs") that primarily serve to complement wide area networks ("WANs"). This is quite distinct from offering a wireless WAN ("WWAN") substitute. Wi-Fi nodes have flourished in enterprises as high-speed fiber connections became available; similarly, residential adoption has soared as companies extend cable modem, digital subscriber line ("DSL"), and fiber subscriptions to U.S. households. In this context, the driver of demand for unlicensed devices is the deployment of the WANs, which rely on private property rights to "spectrum in a tube." 65 This causality is more easily seen, perhaps, with cordless phones, an appendage of fixed networks. There, the clarity of the symbiotic economic relationship has generally prevented commentators from asserting that plain-old telephone service can more efficiently be supplied using a "spectrum commons." It would be nonsensical to claim that the use of the edge device (the cordless handset) was in any way undermining the utility of the ownership rights to the fixed network and the bandwidth created by its investors.

Unlicensed frequencies are not "open access" regimes that enable users to appropriate spectrum resources without constraint. ${ }^{66}$ Nor are unlicensed bands organized within a "commons," where collective resource owners set usage rules to maximize joint returns. ${ }^{67}$ Group owners do not set resource

65. The expression describes wired communications, which utilize the same electromagnetic spectrum as employed in wireless communications but create additional capacity by housing signals in constructed conduits.

66. The law and economics literature recognizes four standard property regimes: open access, state property, common property, and private property. See Dean Lueck \& Thomas J. Miceli, Property Law, in 1 HANDBOOK OF LAW AND ECONOMICs 183, 190-200 (A. Mitchell Polinsky \& S. Shavell eds., 2007). The U.S. spectrum regime has not, strictly speaking, nationalized airwaves or privatized airwaves. Rather, the law is that the public owns the airwaves, with the federal government regulating access so as to protect these public resources. See Thomas W. Hazlett, The Wireless Craze, the Unlimited Bandwidth Myth, the Spectrum Auction Faux Pas, and the Punchline to Ronald Coase's 'Big Joke": An Essay on Ainvave Allocation Poligy, 14 HARV. J.L. \& TECH. 335, 459-61 (2001). As a practical matter, this arrangement constitutes state ownership, also known as administrative allocation. Resource use is determined by state regulators, not by private or group owners.

67. This is the key characteristic of the self-organizing commons studied in such classic works as ELINOR OSTROM, GOVERNING THE COMMONS (1990). 
appropriation terms; government regulators do. These regulators evaluate the trade-offs for adapting different rules on behalf of the public. Regulation of unlicensed bands creates non-exclusive use rights, and the conditions imposed exclude particular types of behavior so as to protect others. For example, a high-powered TV broadcast station is not allowed to blast emissions, and thus diminish opportunities for low-power radios to provide home networking links in the same market. This is intended to limit conflicts between rival users of a scarce resource, ${ }^{68}$ rather than risk resource dissipation due to unproductive competition for rights. ${ }^{69}$

Property rules are an antidote to the "tragedy of the commons." Where entirely unrestricted access prevails and scarcity exists, the marginal user will crowd into the "free" resource even as the cost borne by the group of users exceeds the newly created benefit. The standard example is an open pasture that becomes "over-grazed" by the owners of cattle, each of whom realizes some gain until the resource is destroyed for all. $^{71}$

Perhaps because of the compelling manner in which the "over-grazing" problem is formulated, it is often missed that the regulation of unlicensed devices-prescriptions on technology standards and power limits-is just another approach to avert a tragedy of the commons. The regime seeks to permit some behaviors and to block others. The proper test of social efficiency is not whether "interference" has been reduced or eliminated, but whether the most valuable outcomes result. ${ }^{72}$

Three implications arise. First, anarchy does not reign. The power limits and technology restrictions imposed by regulators protect some applications and users at the expense of others. Scarcity is not eliminated; indeed, the effort to advance what Benkler labels a "well regulated commons" rejection of open access. Allocating spectrum for unlicensed usage necessarily excludes certain wireless alternatives, implicating trade-offs that need not be made in the case of true resource abundance.

Second, tragedy of the commons may obtain even when there is little or no interference between users. Markets that experience over-utilization yield the most widely recognized "tragedy," but rules to mitigate resource

68. See Harold Demsetz, Toward a Theory of Property Rights, 57 AM. ECON. REV. 347 (1967).

69. See Henry E. Smith, Exclusion Versus Governance: Two Strategies for Delineating Property Rights, 31 J. LEGAL STUD. 453 (2002).

70. Garret Hardin, The Tragedy of the Commons, 162 SCIENCE 1243 (1968).

71. See id. at 1244.

72. Coase, supra note 21 , at 27.

73. Benkler, Overcoming Agoraphobia, supra note 58, at 394. 
dissipation can easily result in under-utilization, which is equally inefficient. Such an outcome includes the instance where investments in technology, infrastructure, or economic organization-say, paying incumbents to move their wireless operations-are socially efficient but fail to occur due to the lack of spectrum ownership. Market failure of this sort has occurred in unlicensed bands, such as Unlicensed PCS ("U-PCS"), where spectrum allocated for over a decade to data transmissions saw not a single device approved for use by the FCC $^{74}$

Third, even when abundant use is made of unlicensed bands, the allocation may be socially destructive. For example, unlicensed rules may exclude services that are more valuable than the protected activities. Equivalently, the social value created in the use of unlicensed devices may be achieved more economically via exclusive spectrum rights, provided either by market competitors or via the acquisition of bandwidth by a non-profit organization supplying a "spectrum park." The active secondary market in spectrum access vividly demonstrates how device makers can, rather than request unlicensed allocations for the use of their radios, contract with mobile licensees exercising de facto spectrum ownership. Apple arranges for its iPhone customers to access radio spectrum via bulk contracts it arranges with carriers in United States and internationally. Amazon sells its Kindle book reader with embedded wireless functionality for digital content downloads by contracting with the Sprint phone network. General Motors operates its emergency OnStar radio service by contracting with Verizon Wireless. ${ }^{75}$ The market supplies radio spectrum bundled with network services to supply an extremely wide range of applications. Rival application providers effectively bid against each other for available wireless resources. To the degree that regulators make available spectrum inputs with exclusive ownership rights, the standard economic optimization results.

74. For a source discussing the failure of unlicensed PCS, see, e.g., Kenneth R. Carter, Policy Lessons from Personal Communications Services: Licensed us. Unlicensed Spectrum Access, 15 COMMLAW CONSPECTUS 93, 97 (2006) ("II]n 1993 the... FCC assigned PCS spectrum both by licenses awarded in competitive bidding auctions and through an unlicensed model.... It is hard to argue that licensed PCS has not been a huge success at lowering prices and spurring competition with cellular service. Conversely, unlicensed PCS has at best been a very late bloomer, and at worst, dead.") (footnotes omitted).

75. John W. Mayo \& Scott Wallsten, Enabling Efficient Wireless Communications: The Role of Secondary Spectrum Markets, 22 INFO. ECON. \& POL'Y 61, 65 (2010); Thomas W. Hazlett, Modular Confines of Mobile Networks: Are iPhones iPhony? (George Mason Law \& Econ., Research Paper No. 10-01, 2010), http://papers.ssm.com/sol3/papers.cfm?abstract_id= 1533441. 


\section{WI-FI: THE STARBUCKS FALLACY}

The Wi-Fi standard for wireless, high-speed, local-area networks was ratified in $1999 .^{76}$ By 2002, global annual sales of Wi-Fi equipment had exceeded $\$ 1$ billion; ${ }^{77}$ by 2006 , such sales reached an estimated $\$ 3.8$ billion. $^{78}$ The secret of Wi-Fi's success, commons advocates maintain, is that the standard defines low-power, spread-spectrum devices that can operate "without the requirement of spectrum licensing to prevent interference."79 With Wi-Fi, "there is no need for service providers, cell towers, controlled hardware markets, or expensive spectrum licenses."

While Wi-Fi was taking off, comparable wireless data services offered in licensed bands were allegedly doing "exactly the opposite." Al Although wireless phone companies soon began offering high-speed data services, these networks cost ten times more, ${ }^{82}$ and "[n]one... has yet become a mass-market success." ${ }^{83} \mathrm{Wi}-\mathrm{Fi}$, it is suggested, is superior even to high-speed wireline connections: there is "great consternation in the communications industry" about the inadequacies of DSL and cable modem broadband services, and Wi-Fi service "costs half as much."

Even putting aside the factual predicates and premature nature of these arguments, ${ }^{85}$ the comparisons are fatally flawed. First, assuming that unlicensed devices are popular, it does not necessarily follow that more spectrum should be allocated to unlicensed instead of licensed uses. In 2008, U.S. Wi-Fi devices and cordless phones were out-sold by well over an order

76. See IEEE Get Program 802, INST. OF ELEC. \& ELECS. ENG'RS, INC. (IEEE), http://standards.ieee.org/getieee802/802.11.html (last visited Apr. 7, 2011).

77. See Carter, Lahjouji \& McNeil, supra note 37, at 32 (citing Goldman Sachs).

78. Bernie MaHON \& LOUIS Gerhardy, MORGan Stanley, Q1 2006 Global TECHNOLOGY DATABOOK 22 (2006), available at http://www.morganstanley.com/ institutional/techresearch/pdfs/global_techdatabook0306.pdf.

79. WERBACH, supra note 17 , at 23 .

80. Id.

81. Id. at 22 .

82. Id. at 23 (" $[\mathrm{A}] \mathrm{Wi}-\mathrm{Fi}$ network costs ... one-tenth as much as a third-generation cellular network.").

83. Id. at 22 .

84. Id. at 23 .

85. Licensed wireless $3 G$ services have become extremely popular with the advent of smartphones and other advanced wireless devices, while wireline broadband connections (particularly cable modem and new fiber-to-the-premises networks) now offer speeds up to $100 \mathrm{Mbps}$, far in excess of what a Wi-Fi connection provides. See Annual Report and Analysis of Competitive Market Conditions with Respect to Commercial Mobile Services, 24 FCC Rcd. 6185 (2009); Saul Hansell, Cablevision Goes for U.S. Broadband Speed Record, N.Y. TIMES BITS BLOG (Apr. 28, 2009, 12:01 AM), http://bits.blogs.nytimes.com/2009/04/28/ cablevision-goes-for-us-broadband-speed-record/. 
of magnitude by digital TV sets, which garnered $\$ 27$ billion in sales ${ }^{86}$ Yet, the airwaves dedicated to broadcast television are severely misallocated because video signals can be delivered more efficiently on alternative platforms, freeing the TV band for more productive employments. ${ }^{87}$ From a social welfare perspective, the relevant policy question is how incremental bandwidth can best create value. In evaluating trade-offs, it is important to recognize that licensed regimes can provide the same applications as unlicensed spectrum. Just as the private property regime for land governs the supply of public parks, public, private non-profit, or private for-profit enterprises can host diverse spectrum sharing arrangements. ${ }^{88}$ Indeed, this is seen in the operation of mobile networks, which arrange for millions of customers to use specific licensed frequencies. To identify an efficient outcome, the analysis must determine that the costs of pre-empting alternative liberal license allocations are less than unlicensed benefits. No amount of economic activity in unlicensed bands makes the case for allocating more unlicensed spectrum.

Second, as an empirical matter, the social value of the economic activity associated with liberal licenses far exceeds that achieved in unlicensed bands. Licensed WWANs, relying on licensed spectrum, are used by more than 270 million ${ }^{89}$ U.S. subscribers who pay over $\$ 148$ billion $^{90}$ a year and generate at

86. Press Release, CEA, Consumer Electronics Industry Issues 2009 Forecast (Jan. 8, 2009), http://www.ce.org/Press/CurrentNews/press_release_detail.asp?id=11666 (stating that digital TV sets accounted for fifteen percent of the $\$ 172$ billion shipment revenues in 2008).

87. Hazlett, Transition to Yesterday, supra note 19.

88. FCC spectrum policy experts have noted the efficiencies of such an institutional approach:

[When] making decisions about the amount of spectrum allocated to unlicensed use, the government should face the opportunity cost of limiting or foreclosing other use. Just as the government decides how much land to purchase for public parks, it would decide how much spectrum to set aside for unlicensed devices. A market system would also provide the opportunity for private spectrum licensees in flexible bands to compete with the government for the provision of spectrum for lowpower devices, just as private facilities that charge admission compete with public parks. Licensees might find it profitable to do so by charging manufacturers of such devices to operate on their spectrum. This would allow private licensees to compete on the technical protocols and other quality factors instead of relying on government or industry committees.

Kwerel \& Williams, supra note 8 , at 7.

89. CTIA, SEMI-ANNUAL WIRELESS INDUSTRY SURVEY (2008), available at http://files. ctia.org/pdf/CTLA_Survey_Year-End_2008_Graphics.pdf.

90. Id. 
least another $\$ 150$ billion $^{91}$ in consumer surplus. Equipment sales tell a similar story. In 2006, global sales for WWANs using liberal licenses were about $\$ 225$ billion (including handsets), while wireless local area networks ("WLANs"), using unlicensed frequencies, totaled about $\$ 3.8$ billion."

FCC statistics for broadband access in the United States tell the same story. While unlicensed bandwidth is available everywhere for the use of Internet Service Providers ("ISPs"), and while hundreds of wireless ISPs ("WISPs") use airwaves for this purpose, 93 they operate in small deployments, usually in rural areas where low population densities ensure minimal interference. ${ }^{94}$ As a result, unlicensed frequencies, while useful in providing Wi-Fi as a WLAN appendage in millions of homes or businesses that subscribe to wide area broadband services, are virtually non-existent in supplying WAN services themselves. The FCC recorded only 525,000 fixed wireless customers as of year-end 2009, a total which includes ISPs using licensed and unlicensed frequencies, as compared to more than 52 million mobile high-speed data customers (all delivered via licensed spectrum). ${ }^{95}$ In addition, the FCC reported over 80 million fixed high-speed connections (cable modem, DSL, and fiber), services delivered via networks relying on the ownership of spectrum encased in wires. The bottom line: more than 130 million subscribers receive high-speed data service (fixed and mobile) via exclusively owned bandwidth, as compared to just a few hundred thousand

91. Hazlett \& Muñoz, supra note 36, at 425. Professor Jerry Hausman produces consistent estimates using a different model. See Jerry Hausman, Mobile Telepbone, in 1 HaNDBOOK OF TEleCOMMUNiCATIONS ECONOMiCS 563, 585-86 (Martin Cave et al. eds., 2002).

92. MAHON \& GERHARDY, supra note 78 , at $22,24$.

93. The Wireless Internet Service Providers Association ("WISPA") "was founded in 2004 and represents the interests of more than 300 wireless internet service providers (WISPs'), vendors, system integrators and others interested in promoting the growth and delivery of fixed wireless broadband services to Americans. WISPA estimates that more than 2,000 WISPs operate in the United States today." Comments of the Wireless Internet Serv. Provider Ass'n at 2, Inquiry Concerning the Deployment of Advanced Telecommunications Capability to All Americans in a Reasonable and Timely Fashion, and Possible Steps To Accelerate Such Deployment Pursuant to Section 706 of the Telecommunications Act of 1996, as Amended by the Broadband Data Improvement Act, A National Broadband Plan for Our Future, GN Docket Nos. 09-47, -51 \& -137 (Fed. Commc'ns Comm'n Dec. 7, 2009), available at http://fjallfoss.fcc.gov/ecfs/document/view?id=7020351635; WISP Directory, WISPA, http://www.wispdirectory.com/index.php?option=com_mtree\&task= listcats\&cat_id=73\&Itemid=53 (last visited Mar. 3, 2011) (listing 1,845 WISPs in the United States).

94. This is observed in comparing the large number of WISPs relative to the small number of "fixed wireless" subscribers (see infra Table 1), as well as examining the WISP map produced by WISPA. WISP Directory, supra note 93.

95. See infra Table 1. 
subscribers-at most-to WISPs and those accessing the Internet via a "spectrum commons."

Table 1: U.S. Broadband Subscribers (Dec. 2005 to Dec. 2009) ${ }^{96}$

(Thousands of Subscribers)

\begin{tabular}{|lrrrrr|}
\hline & $\mathbf{2 0 0 5}$ & $\mathbf{2 0 0 6}$ & $\mathbf{2 0 0 7}$ & $\mathbf{2 0 0 8}$ & $\mathbf{2 0 0 9}$ \\
ADSL & 19,515 & 25,413 & 29,449 & 30,198 & 30,971 \\
SDSL & 369 & 345 & 293 & 241 & 225 \\
Traditional Wireline & 373 & 545 & 605 & 705 & 716 \\
Cable Modem & 26,558 & 31,982 & 36,507 & 40,273 & 43,128 \\
Fiber & 298 & 894 & 1,849 & 2,884 & 3,975 \\
Satellite & 427 & 572 & 791 & 938 & 1,116 \\
Fixed Wireless & 257 & 483 & 707 & 486 & 525 \\
Mobile Wireless & 3,128 & 22,288 & 51,016 & 25,040 & 52,486 \\
Power Line and Other & 5 & 5 & 5 & 5 & 5 \\
\hline Total Lines & 50,930 & 82,525 & 121,222 & 100,770 & 133,148 \\
\hline
\end{tabular}

The rise and fall of Municipal Wi-Fi networks is also revealing evidence. "Muni Wi-Fi" was widely touted as the next big thing in broadband in 2006 and 2007..$^{77}$ At one point, there were plans to deploy scores of networks covering major urban areas such as Philadelphia, Houston, Boston, Chicago, Los Angeles, Atlanta, and San Francisco. ${ }^{98}$ By 2008, however, virtually all of these plans had collapsed." Access to "free" airwaves was supposed to provide cheap service, but the structure of property rightswith regulatory limitations on power, technology, and the inability to exclude (and, therefore, contract with) potentially rivalrous spectrum users-has rendered the model of limited practical use. ${ }^{100}$ Gradually, this reality has set

96. FED. COMMC'NS COMM'N, HIGH-SPEED SERVICES FOR INTERNET ACCESS: STATUS AS OF DECEMBER 31, 2009, tbl.7 (2011). Note that the large drop in mobile wireless subscribers, 2007 to 2008, was caused entirely by a switch in FCC accounting practices. Previously, all high-speed capable wireless devices used by subscribers were counted. Beginning in the 2008 data, only subscriptions "which [include] a data plan for transferring, on a monthly basis, either a specified or an unlimited amount of data to and from Internet sites of the subscriber's choice" were included in the "Mobile Wireless" total. Id. at 81.

97. See Robert McChesney \& John Podesta, Let There Be Wi-Fi, WASH. MONTHLY, Jan.Feb. 2006, available at http://www.washingtonmonthly.com/features/2006/0601.podesta.html.

98. Thomas W. Hazlett, Philadelphia Freedom, ARS TECHNICA (Dec. 22, 2008, 11:05 PM), http://arstechnica.com/telecom/news/2008/12/muni-wifi-fcc-free-wireless.ars.

99. Id.

100. This is why the hundreds of private WISPs did not see such services as profit opportunities, leading community activists and policymakers to seek local government support. The deals struck by municipalities included subsidies, monopoly rights to access 
in. "Story after story after story highlight [s] how wide-area WiFi is a lot more complicated than many in the industry (and the press) would have you believe."101

At the end of the day, Wi-Fi offers only very limited substitution possibilities for high-speed DSL, cable, fiber, or wide area wireless. As commons advocates themselves acknowledge, it is "a short-range technology designed primarily for connections to a nearby hotspot."102 Wi-Fi radios typically operate at such low power that "[e]ven if every home in a neighborhood had a Wi-Fi access point, few of those nodes would see one another."103 Wi-Fi devices, in short, rarely interfere with each other because they provide such limited range. The secret of Wi-Fi's success is the secret of Wi-Fi's failure. By contrast, DSL, cable modems, fiber, and wireless broadband service (e.g., EV-DO) provide wide-area coverage across cities and markets, cost-effectively scaling to national and international networks.

Some predict, however, that more and better Wi-Fi lies ahead and that radio-frequency engineering advances will overcome all of these limitations. ${ }^{104}$ Such range-extending technology includes phased-array antennas, mesh networking boxes that automatically create ad hoc mesh networks with each other, a follow-up standard (802.16) for wireless metropolitan-area-network ("MAN") technology, and so forth. ${ }^{105}$

There is no doubt that innovative advances will come, but they will not be restricted to use in unlicensed bands. Rapid technological change is also producing disruption in networks using licensed spectrum. Airwaves are

$\overline{\text { street lights (for placement of wireless nodes), or exclusive contracts with public agencies }}$ (anchor tenants).

101. Michael Masnick, Can Mesh WiFi Solve the Net Neutrality Issue?, TECHDIRT (June 20, 2006, 3:24 AM), http://techdirt.com/articles/20060620/0318228.shtml.

102. WERBACH, supra note 17 , at 39 ("Basic WiFi or its variants ... cannot simply be put into service for last-mile deployments.").

103. Id. (emphasis added).

104. See, e.g., David Weinberger, The Myth of Interference, SALON (Mar. 12, 2003), available at http://www.salon.com/tech/ feature/2003/03/12/spectrum/print.html.

105. WERBACH, supra note 17, at 39; Björn Wellenius \& Isabel Neto, The Radio Spectrum: Opportunities and Cballenges for the Developing World 7 (World Bank Policy, Working Paper No. 3742, 2005) ("Other recent innovations include smart radios and antennas, software-defined radios, cognitive radios, and mesh, ad-hoc, or viral networks. As a group, these technologies enable users not to cause insurmountable interference to each other even when transmitting at the same time, in the same place, and on the same parts of the spectrum.') (footnotes omitted); see also Fulvio Minervini, Emerging Technologies and Access to Spectrum Resources: The Case of Short-Range Systems, 67 COMM. \& STRATEGIES 107, 112-15 (2007), available at http://mpra.ub.uni-muenchen.de/6786/1/MPRA_paper_6786.pdf (arguing that advanced antennas and mesh networks enhance access to the radio spectrum, while not disrupting the traditional framework of spectrum usage). 
agnostic to regulatory regimes; users and investors are not. When network owners can optimize a given spectrum space by contracting to share it, they are often able to bring more resources and greater social coordination to bear. This is observed in liberal-licensed spectrum, which is being far more intensely developed and utilized, in economic value terms, than spectrum allocated to traditional licenses or unlicensed bands. As U.S. smartphone sales reach $\$ 14$ billion per year, ${ }^{106}$ iconic wireless innovations such as the Apple iPhone and RIM Blackberry rely on WWANs, and the licensed spectrum they use, to revolutionize communications. Hence, as the benefits of using unlicensed spectrum rise, the opportunity costs of taking allocations away from liberal licenses rise pari passu.

Which brings us to Starbucks. With all options other than low-power radios eliminated (through government regulation), exclusive rights in real estate may afford some of the protections of exclusive rights in spectrum. Users can themselves limit the number of transmitters and/or receivers competing for access to spectrum in corporate offices, on university campuses, and in Starbucks coffee shops. ${ }^{107}$ Intel, for example, carefully restricts unauthorized use of unlicensed frequencies within its corporate office space. ${ }^{108}$ Carnegie Mellon protects the spectrum on its campus by effectively "privatizing the commons," i.e., carefully selecting what services and users to include in its network (and thereby which to exclude), while adopting technologies and distributing wireless access points to control interference problems. ${ }^{109}$ This is not the "end of scarcity," but the operations of a property system to manage competing, mutually exclusive activities. ${ }^{110}$ Conflicts still exist, and "open access" would be socially destructive.

106. CEA estimates 2009 U.S. sales of 37 million smartphones, with total revenues of $\$ 14$ billion. CEA Database, supra note 4 . This is about forty times cordless phone sales. WiFi sales are not charted by CEA.

107. See Hazlett \& Muñoz, supra note 27, at 264-66.

108. See Mike Chartier, Intel, Local Spectrum Sovereignty: An Inflection Point in Allocation, in PROCEEDINGS OF THE INTERNATIONAL SYMPOSIUM ON ADVANCED RADIO TECHNOLOGIES 29, 32-33 (2004), available at http://www.its.bldrdoc.gov/pub/ntia-rpt/04 409/04 - 409.pdf ("Failure to fulfill the above terms and conditions [for non-IT WLANs] will result in I.T.'s disconnecting and or taking possession of the Experimental W-LAN Access Points.").

109. Airspace Guideline for $2.4 \mathrm{GHz}$ Radio Frequency at Carnegie Mellon University, cited in Chartier, supra note 108, at 33 ("While we will not actively monitor use of the airspace for potential interfering devices, we will seek out the user of a specific device if we find that it is actually causing interference and disrupting the campus network. In these cases, Computing Services reserves the right to restrict the use of all $2.4 \mathrm{GHz}$ radio devices in university-owned buildings and all outdoor spaces on the Carnegie Mellon Campus.").

110. Weinberger, supra note 104. 
In short, regulatory exclusions police Starbucks stores' airwaves and limit unlicensed frequencies to the use of cordless phones, wireless routers, or other similar low-power devices. Starbucks may eliminate some further conflicts; instead of inviting any and all ISPs to set up local area networks in its stores, it designates and contracts with an exclusive provider. ${ }^{11}$ The service may require paying a fee for access, as it was offered for many years; free access may be extended to paying customers, a model to which Starbucks then switched, ${ }^{112}$ or access may be open to all who receive the signal, a model to which Starbucks more recently switched. ${ }^{113}$ Prior to opening access to all, the "spectrum commons" had been locally privatized, allowing a service supplied solely by AT\&T, one of the nation's largest mobile wireless carriers. ${ }^{114}$ Such services provide social value. What remains unclear, given the lack of a market for the spectrum inputs consumed, is whether the opportunities consumed by the government's spectrum allocation do not exceed these benefits. Net social value may well have been higher had companies like Starbucks, AT\&T, and Cisco (a large maker of WiFi hotspot routers) been forced to economize on spectrum resources by purchasing them in the market-just as AT\&T does when acquiring billions of dollars worth of liberal licenses, making wireless access available to its millions of mobile subscribers.

What works in a Starbucks does not necessarily produce benefits that exceed social opportunity costs. Nor does it scale to other useful wireless applications. Indeed, the rules that allow the beneficial deployment of short range devices in a home or enterprise make the deployment of WANsparticularly for services involving the economic and technical complexity of mobile access-extremely problematic. The local Wi-Fi link that connects clustered, fixed users to a WAN relies on private property rights to radio

111. In 2008, Starbucks switched its designated Wi-Fi partner from T-Mobile to AT\&T. Steve Stroh, AT\&́T Upgrades $3 G$ Network and Takes Over Starbucks Wi-Fi, TECHREPUBLIC (Feb. 11, 2008), http://www.techrepublic.com/blog/wireless/at-t-upgrades-3g-networkand-takes-over-starbucks-wi-fi/185.

112. David Sarokin, How To Get Free Wi-Fi at Starbucks, EHow.COM (Aug. 30, 2009), http://www.ehow.com/how_2269126_wifi-starbucks.html.

113. Jennifer van Grove, How Starbuckes Plans To Capitalize on Free Wi-Fi, MASHABLE (Aug. 12, 2010), http://mashable.com/2010/08/12/starbucks-digital-network/. It is interesting to note that, while customer access may be free to those in (or near) a Starbucks, company websites featured on the start-up page are limited to Starbucks' strategic partners. In the "Starbucks Digital Network," the store chain receives a cut of online revenues generated by companies like Apple, Rodale, and the New York Times, which are granted preferential access to Wi-Fi users in exchange. Id.

114. See High Speed Wireless Internet Access, STARBUCKS, http://www.starbucks.com/ coffeehouse/wireless-internet (last visited Jan. 21, 2011). 
spectrum to transport data to distant networks. Just as the cordless phone depends on, and does not replace, the telephone network, the cordless PC depends on, and does not displace, the wired or wireless WAN.

\section{A. Broadcasting Licenses: A Blast From the PASt}

According to the exclusivity critique, the central problem in spectrum is that ownership rights result in the waste of bandwidth. In any given geographic area, many channels in a licensed system are empty much of the time. ${ }^{115}$ This was not always the case, according to spectrum commons advocates. Licensing was perhaps needed in 1927, but only because the broadcast radios of that era were not smart. Things are very different today. Technology, they claim, makes once-scarce spectrum plentiful. ${ }^{116}$ To prove this proposition, commons advocates have measured "actual usage of the most active channels of the broadcast bands ... during peak hours in the highly populated, Dupont Circle area of Washington, DC."117 These

115. WERBACH, supra note 17, at 8; Lynnette Luna, Start-up Looks To Jump Start Secondary Spectrum Market, FierCEBROADBANDWIRELESS (Mar. 10, 2008, 7:59 AM), http://www. fiercebroadbandwireless.com/story/start-up-looks-to-jump-start-secondary-spectrum-mark et/2008-03-10 (quoting Rick Rotondo, Spectrum Bridge's Vice President of Marketing, stating that "in any given time and place, 80 percent to 94 percent of all allocated spectrum in the U.S. goes unused"); see Promoting Efficient Use of Spectrum Through Elimination of Barriers to the Development of Secondary Markets (Promoting Efficient Use), 15 FCC Rcd. 24,203 , \ 2 (2000) ("[R]adio spectrum may be used inefficiently by its current licensees or even lie fallow, especially in rural areas, limiting availability of valuable services to many."); Michael Calabrese, The End of Spectrum 'Scarrity': Building on the TV Bands Database 'To Access Unused Public Airwaves 1, 16 (New Am. Found., Working Paper No. 25, 2009), available at http://www.newamerica.net/files/Calabrese_WorkingPaper25_EndSpectrumScarcity.pdf ("[I]n every community across the country, large swaths of valuable spectrum lie fallow the majority of the time. This underutilized spectrum represents enormous, untapped, public capacity for high-speed and pervasive broadband connectivity.... [S] tudies show that only a fraction of even prime frequencies below $3 \mathrm{GHz}$ are in use, even in the largest cities, at any particular place or time. Federal agencies sit on hundreds of $\mathrm{MHz}$ that are unused in most areas; and many private licensees are warehousing spectrum, particularly in rural areas."); see also Spectrum Reports, SHARED SPECTRUM CO., http://www.sharedspectrum.com/papers/ spectrum_reports/ (last visited Mar. 23, 2011) (showing spectrum occupancy measurements in six east coast locations including New York City, New York).

116. E.g., WERBACH, supra note 17, at 21 ("Technology is making the wireless world look more and more like the ocean."); see also, e.g., U.S. GEN. ACCOUNTING OFFICE, GAO03-277, TELECOMMUNICATIONS: COMPREHENSIVE REVIEW OF U.S. SPECTRUM MANAGEMENT WITH BROAd STAKEHOLdER INVOLVEMENT IS NEEDED 9, 55-56 (2003) ("[A]dvances in technology could also help to accommodate more services and users."); Paul Kolodzy, Communications Policy and Spectrum Management, in COGNITIVE RADIO TECHNOLOGY 64 (Bruce A. Fette ed., 2006) ("SDRs and other advanced technologies can potentially alleviate many of the conflicts by making spectrum more plentiful through more efficient access.").

117. WERBACH, supra note 17 , at 8. 
measurements are believed to establish that "[m]ost of the spectrum is empty in most places most of the time."

But the measurements equate emitted radiation with actual usage, disregarding the economic value generated. Under this scale, a broadcast tower emitting a 1,000,000-watt test pattern signal is not a waste of spectrum and electricity, but a highly utilized frequency band. And even if spectrum use measurements were correctly done, they would reveal an even more sweeping indictment: the absence of effective airwave ownership cripples the process by which frequency spaces are bid into their highest-valued uses. ${ }^{119}$ Administrative allocation leaves regulators in charge of resource choices, meaning that interest group competition rules the roost. The ugly result is that airwaves are systematically under-utilized, maximizing not consumer welfare but the political interests of influential coalitions.

The historical origins of this system are instructive. In 1920, Westinghouse inaugurated the nation's first successful radio station, KDKA, in Pittsburgh. ${ }^{120}$ Hundreds of other new stations began broadcasting shortly thereafter. Each transmitter was required to obtain a license from the Department of Commerce under the 1912 Radio Act. ${ }^{121}$ While anyone could register for a license, and the Commerce Department had no basis on which to deny them, the agency was permitted to issue licenses under terms "minimizing interference." 122 From 1921-1925, the Department established rules for allocating frequency slots on a first-come, first-served basis. ${ }^{23}$ The

118. Id.; see also Max Vilimpoc \& Mark McHenry, Dupont Circle Spectrum Utilization During Peak Hours, NEw AM. FOUND. (2003), http://www.newamerica.net/files/nafmigration/ archive/Doc_File_183_1.pdf.

119. See Comments of 37 Concerned Economists at 7, Promoting Efficient Use, WT Docket No. 00-230 (Fed. Commc'ns Comm'n Feb. 7, 2001) (encouraging the FCC to "adopt market-oriented rules opening the radio spectrum and capturing its full potential for society"); Gerald R. Faulhaber, The Future of Wireless Telecommunications: Spectrum as a Critical Resource, 18 INFO. ECON. \& POL'Y 256 (2006); Hazlett, supra note 66; Gregory L. Rosston \& Jeffrey S. Steinberg, Using Market-Based Spectrum Policy To Promote the Public Interest, 50 FED. Comm. L.J. 87 (1997); Pablo T. Spiller \& Carlo Cardilli, Towsards a Property Rights Approach to Communications Spectrum, 16 YALE J. ON REG. 53 (1999); Lawrence J. White, Propertyzing' the Electromagnetic Spectrum: Wby It's Important, and How To Begin, 9 MEDIA L. \& POL'Y (2000).

120. Joseph E. Baudino \& John M. Kittross, Broadcasting's Oldest Stations: An Examination of Four Claimants, 21 J. BROAD. 61 (1977); see also Milestones: Westinghouse Radio Station KDKA, 1920, IEEE GLOBAL HISTORY NETWORK (June 1994), http://www.ieeeghn.org/wiki/ index.php/Milestones:Westinghouse_Radio_Station_KDKA,_1920.

121. See Thomas W. Hazlett, The Rationality of U.S. Regulation of the Broadcast Spectrum, 33 J.L. \& ECON. 133, 135 (1990).

122. 1912 Radio Act, ch. 287, \4, 37 Stat. 302, 304.

123. See Clarence C. Dill, Radio Law: Practice and Procedure 66-71 (1938) (discussing changes to regulations by the Secretary of Commerce in the 1920s). 
government then delayed or encumbered new licenses (mandating timesharing agreements, for example) to effectively protect existing stations from encroachment by entrants. ${ }^{124}$

The de facto property system, based on common law principles of priority-in-use or right of user, successfully launched the emerging medium. By the mid-1920s, and prior to any "public interest" licensing law, radio had become an extremely popular mass-market commodity. ${ }^{125}$ Yet key policymakers were not happy with this result, as the first-come, first-served approach severely limited their degree of freedom. The Secretary of Commerce, Herbert Hoover, was vocal in his support for more administrative discretion, as was Senator Clarence C. Dill (D-WA), a congressional leader in the area. ${ }^{126}$

Just as importantly, large incumbent radio stations sought a greater level of security. While priority-in-use protected their signals, it also created risk of competitive entry. That is to say, new spectrum could potentially be claimed by new rivals. The broadcast stations sought a regulatory solution under which barriers could be legally erected to prevent this; the standard of "public interest, convenience, or necessity"-first suggested by the newlyformed National Association of Broadcasters in 1925-was such a rule. ${ }^{127}$ Large commercial radio stations formed a coalition with key policymakers and ultimately gained passage of the Radio Act of 1927, placing radio broadcasting under the new Federal Radio Commission ("FRC"). ${ }^{128}$ The FRC was empowered to license transmitters, assign frequencies, prescribe service limits, and approve the locations and power levels of transmitters according to "public interest" criteria. These policies were carried forward by the Communications Act of 1934, which transplanted the FRC into a newlyconstituted FCC. ${ }^{129}$

Both policymakers and powerful incumbent stations gained from the bargain in the 1927 and 1934 Acts. Regulators obtained considerable control

124. Hazlett, supra note 121, at 143-47.

125. Thomas W. Hazlett, Physical Scarcity, Rent Seeking, and the First Amendment, 97 COLUM. L. REV. 905, 913-19 (1997).

126. Hazlett, supra note 121, at 162-63. Dill was a principal author of the Radio Act of 1927.

127. DILL, supra note 123 , at 89 .

128. Radio Act of 1927, ch. 169, 44 Stat. 1162 (repealed 1934). The Interstate Commerce Commission retained authority over common carrier use of radio spectrum.

129. Communications Act of 1934, ch. 652, 48 Stat. 1064 (codified as amended at 47 U.S.C. $\int 151-615 \mathrm{~b}$ (2006)). The Communications Act of 1934 and its amendments, including those in the 1996 Telecommunications Act, are posted by the FCC at http://www.fcc.gov/Reports/1934new.pdf. 
over the operations of licensees, including the ability to influence program content. ${ }^{130}$ And because license holders would be restricted to explicitly authorized activities, competition between licensees could be limited. New services, technologies, and business models were barred-forming, effectively, a government-enforced cartel. Later, law and economics scholars would characterize the general arrangement as "Taxation by Regulation.",131 Reducing competition via legal barriers increased profits; regulators then redirected some of the economic gains towards "public interest" expenditures.

FCC spectrum allocation proved bureaucratically tidy but economically inflexible. First, the FCC would zone the real estate. It assigned large blocks of spectrum for particular uses such as AM radio or Very High Frequency TV ("VHF TV"). Then it sliced each block into smaller licenses and assigned them to individual firms. ${ }^{132}$ Licensees got no "property rights" in spectrum; ${ }^{133}$ licenses typically expired after eight years, ${ }^{134}$ and they could not be transferred without Commission approval. ${ }^{135}$ Between 1927 and the early 1970s, the FCC promulgated a dense web of rules governing license retention and alienability, transmission and programming rights, signal privacy, and content - rules like the "fairness doctrine" or an obligation to air programs deemed educational for children. ${ }^{136}$ Broadcasters, for example, were barred early on from using their main frequencies and facilities to transmit private, addressed messages to specific receivers, essentially telephone or telegraph services. ${ }^{137}$

The traditional licensing approach results in vast waste of bandwidth precisely because licensees are given no ownership in the underlying spectrum but are instead restricted to specific uses of a radio technology as defined by the regulator. Without spectrum ownership, private parties cannot transact to make more valuable use of idle frequencies. The tragedy is not the

130. Hazlett, supra note 121, at 158-63.

131. Richard A. Posner, Taxation by Regulation, 2 BELL J. ECON. \& MGMT. SCI. 22 (1971).

132. Hazlett, supra note 66, at 337-50. See generally John O. Robinson, Spectrum Management in the United States: An Historical Account (Fed. Commc'ns Comm'n, O.P.P. Working Paper No. 15, 1985).

133. See 47 U.S.C. $\$ \int 301,304,309(\mathrm{~h})(1)(2006)$; see also Radio Act of $1927 \$ 1$.

134. 47 U.S.C. $\$ 307$ (c).

135. Id. $₫ 310(\mathrm{~d})$; see also Radio Act of $1927 \rrbracket 12$.

136. See generally Glen O. Robinson, The Federal Communications Commission: An Essay on Regulatory Watchdogs, 64 VA. L. REV. 169 (1978).

137. See Scroggin \& Co. Bank, 1 F.C.C. 194 (1935); Bremer Broad. Co., 2 F.C.C. 79 (1935). 
overuse of the commons, but its underuse. ${ }^{138}$ In theory, the regulatory agency could prevent this, but it is not vested with real ownership, is unable effectively to finance productive, spectrum-enhancing investments, and receives no economic reward for generating extra social value. These misaligned incentives create "non-market failure."139

Shifting to liberal licenses-granting wireless service providers exclusive rights and broad flexibility to use allocated spectrum-remedies this tragedy, thereby creating the legal institutions to support Coasean contracting. These unleash incentives to invest in complementary assets that improve the productivity of airwaves, creating value for wireless users, some of which can then be captured by spectrum owners. This property structure enables complex organizational efforts, including those involving billions of dollars in risk capital dependent on the actions of millions of customers far into the future.

In sum, the case for un-licensing spectrum today is based on the deficiencies of a broadcast licensing policy established in the 1920s, a framework largely repudiated by spectrum rights that emerged in the United States and elsewhere in the 1980s and 1990s. Broadcasting is no longer dominant, having been eclipsed in value terms by the world of mobile communications. The licenses that enable those emerging markets are sufficiently liberal as to resemble de facto ownership of radio spectrum. The traditional licensing regime, despite the continued support of survivalists in politics and broadcasting, is universally recognized as obsolete. Grounded in a critique of the Radio Act of 1927, the case for un-licensing spectrum targets a corpse, oblivious to the thundering herd of exclusive spectrum rights now dominating communications markets.

\section{WIRELESS CARRIERS AND LIBERAL LICENSES}

\section{A. The NeXtel "Reallocation"}

One group of "broadcasters" has already completed a very successful transition from the old ways of licensing to the new. Radio dispatch services—used by taxicab companies, for example-once operated much like radio stations, under licenses that narrowly specified the service to be

138. Or, some call it a tragedy of the anticommons. See MiCHAEL Heller, THE GRIDLOCK ECONOMY (2008).

139. Charles WOlF, JR., Markets or Governments: ChOOSInG BetWeen IMPERFECT ALTERNATIVES 57 (1988) (describing "non-market failure" as a situation in which the incentives of government policymakers do not reliably produce efficient outcomes, analogous to "market failure"). 
provided and the technology to be used. In 1987, a former FCC lawyer named Morgan O'Brien teamed up with an investment banker and began buying up dispatch companies — and their Specialized Mobile Radio ("SMR") licenses-across the country. ${ }^{140}$ Their company, FleetCall, then put forward a plan asking regulators to approve a technical upgrade for SMR licenses: they sought the right to deploy digital instead of analog radios. ${ }^{141}$

The license modification also sought permission to use the extra capacity made possible by the technical upgrade for cellular phone calls. Such requests are met with strong opposition from established interests and are typically deterred: why spend scarce resources on such low-probability payoffs? But Morgan O'Brien believed that his knowledge of the Commission and the timing of this proposal-with the explosion of cellular use and the drift in deregulatory philosophy-brightened FleetCall's prospects. Some years and $\$ 2$ million in legal fees later (as against an estimated \$25 million in fees for opponents of the requested rule changes), ${ }^{142}$ the underdog received approval. $^{143}$

FleetCall adopted a new Motorola technology (iDEN, based on Time Division Multiple Access or "TDMA"), greatly expanding network capacity. ${ }^{144}$ In March 1993, the "taxi dispatch" company renamed itself Nextel. ${ }^{145}$ In 1995, wireless pioneer Craig McCaw invested $\$ 1.1$ billion. $^{146}$ Motorola improved iDEN to enable data and fax communications in addition to voice, along with two-way dispatch and paging applications. ${ }^{147} \mathrm{By}$ 2003, FleetCall had acquired spectrum rights in the 700,800 , and $900 \mathrm{MHz}$ bands $^{148}$ and was operating one of the largest digital networks in the country. ${ }^{149}$ FleetCall executed a "spectrum swap" with the FCC, reducing

140. See K. Maney, Nextel's Morgan O'Brien Kept the Faith and, Boy, Has It Paid Off, USA TODAY, Dec. 15, 2004, at 3B; see also O. CASEY CORR, MONEY From THIN AIR: THE STORY OF CRAIG MCCAW 235-48 (2000).

141. The technological innovation would have violated license terms-hence the petition for license modification.

142. Hazlett, supra note 66, at 388.

143. See Request of Fleet Call, Inc. for Waiver and Other Relief To Permit Creation of Enhanced Specialized Mobile Radio Systems in Six Markets, 6 FCC Rcd. 1533, \ 36 (1991).

144. New Motorola Digital Technology Increases Channel Capacity as Much as Six Times, Promises Enbanced Services to Thousands of Customers, PR NEwSWIRE, Sept. 20, 1991.

145. See Nextel History, SPRINT, http://shop2.sprint.com/en/about/corporateinfo/ company_history5.shtml (last visited Apr. 7, 2011).

146. See Motorola Licenses Radio System, MrCaw Invests in Nextel, NewSBYTES, Apr. 5, 1995.

147. Motorola Announces Commercial Availability of iDEN Tecbnology Enbancement, PR NEWSWIRE, June 17, 1996.

148. See Nextel Commc'ns, Inc., Annual Report (Form 10-K), at 6 (Mar. 27, 2003).

149. Press Release, Nextel, Nextel Completes Another Industry First (July 29, 2003), http://findarticles.com/p/articles/mi_m0EIN/is_2003_July_29/ai_105986364. 
interference that its phones caused with adjacent public service (fire, police, etc.) frequencies, receiving spectrum holdings in the $1.9 \mathrm{GHz}$ band. ${ }^{150}$ It then acquired several 2.1 and $2.5 \mathrm{GHz}$ licenses and established partnerships and roaming agreements, giving it national coverage. ${ }^{151}$ In 2005, Nextelproviding push-to-talk walkie-talkie service, wireless data services, wireless internet access, and short messaging to roughly seventeen million customers $^{152}$ — was sold to Sprint for an acquisition price of $\$ 35$ billion. ${ }^{153}$

\section{B. FCC REFORMS}

Other wireless carriers acquired their spectrum assets more directly. Verizon Wireless, ${ }^{154}$ AT\&T Mobility, ${ }^{155}$ T-Mobile, ${ }^{156}$ and other mobile networks received cellular licenses-initially issued by the government in lotteries ${ }^{157}$-largely through secondary market purchases. The early cellular networks were required to build systems incorporating the analog Advanced Mobile Phone Systems ("AMPS") standard. In 1988, the FCC relaxed this requirement, allowing operators to upgrade to a digital standard of their choosing, though still requiring that they maintain the old AMPS system as

150. Roy Mark, Nextel Finalizes Spectrum Swap, WI-FI PLANET (Feb. 7, 2005), http://www.wi-fiplanet.com/news/article.php/3469601; Improving Public Safety Communications in the $800 \mathrm{MHz}$ Band, 19 FCC Red. 14,969, ๆ 61 (2004).

151. Nextel Commc'ns, Inc., Annual Report (Form 10-K), at 5 (Mar. 15, 2005).

152. See Press Release, Nextel, Nextel Reports Strong Results (July 21, 2005), http://www.thefreelibrary.com/Nextel+Reports+Strong+Results.-a0134233871.

153. Sprint, Nextel Complete Merger, DigiTAL TRENDS (Aug. 12, 2005), http://www.digitaltrends.com/mobile/sprint-nextel-complete-merger/.

154. Verizon was formed from the merger of Bell Atlantic and GTE. Bell Atlantic had previously merged with NYNEX and AirTouch (originally the wireless arm of Pacific Bell). Verizon owns fifty-five percent of Verizon Wireless; Vodafone, a global mobile carrier based in the United Kingdom, owns the other forty-five percent. Bill Greenberg, History of the Big Four US Carriers, PHONESCHOLAR.COM (Feb. 7, 2011), http://www.phonescholar.com/ verizon/a-history-of-the-big-four-us-carriers.

155. SBC (which had previously merged with Ameritech and Pacific Telesis) jointly owned Cingular with BellSouth (with SBC owning sixty percent and BellSouth forty percent). In October 2004, Cingular merged with AT\&T Wireless; by this time, SBC had acquired the long distance operator AT\&T. Following the merger, SBC changed its name to AT\&T. In 2006, AT\&T acquired BellSouth. Id.

156. T-Mobile was created by the 2000 purchase of U.S. carrier VoiceStream by Deutsche Telekom, a German telecommunications provider spun off from the former state monopoly. VoiceStream, Deutsche Telekom Seal $\$ 50.7 B$ Deal, REUTERS, July 24, 2000, available at http://www.crn.com/news/channel-programs/18809269/voicestream-deutsche-telekomseal-50-7b-deal-reuters.htm.

157. Thomas W. Hazlett \& Robert J. Michaels, The Cost of Rent-Seeking: Evidence from the Cellular Telephone License Lotteries, 39 S. ECON. J. 425 (1993). 
well. ${ }^{158}$ That was an important policy pivot, which pointed the way to further liberalization.

In 1993, with the FCC getting ready to assign new PCS licenses, adding competitors to cellular, Congress ordered that all wireless phone rivals be regulated under a unified Commercial Mobile Radio Service ("CMRS") designation. ${ }^{159}$ Cellular, PCS, and SMR-the reinvented taxi dispatcherwould operate as direct rivals with broad, flexible-use spectrum rights. ${ }^{160}$ This codified what the FCC had already begun to implement, pre-empted state rate regulation, and for the first time permitted licenses to be assigned through competitive bidding. ${ }^{161}$ Chairman Reed Hundt remarked: "[W]e had totally deregulated the wireless industry."

\section{MARKETPLACE SPECTRUM AlLOCATION}

Carriers seized the opportunity to deploy a range of digital voice technologies-not only TDMA, but also GSM (the standard used most widely in the rest of world), and Code Division Multiple Access ("CDMA") (a rival standard developed by San Diego-based Qualcomm). These technologies have permitted aggressive upgrades over the years to third and fourth generation (" $3 G$ " and " $4 G$ " in industry parlance) systems that have paved the way for innovative wireless services and devices. GSM networks, which AT\&T and T-Mobile deploy, have evolved from EDGE to UMTS to HSDPA technology. CDMA networks, which Verizon and Sprint have deployed, evolved from IS-95 to CDMA2000 1x to EV-DO to EV-DO Rev A. All four wireless carriers have recently begun yet another new upgradeto Long Term Evolution ("LTE") technology, which offers download speeds to mobile handsets of up to $100 \mathrm{Mbps}$.

This progression occurs seamlessly, without disturbing network users, but requires vast resources: over $\$ 24$ billion annually in network capital expenditures. ${ }^{163}$ Customers and operators spend billions more on handsets,

158. Amendment of Parts 2 and 22 of the Commission's Rules To Permit Liberalization of Technology and Auxiliary Service Offerings in the Domestic Public Cellular Radio Telecommunications Service, 3 FCC. Rcd. 7033 (1988).

159. Omnibus Budget Reconciliation Act of 1993, Pub. L. No. 103-66, Title VI, $\$ 6002(\mathrm{~b})(2)(\mathrm{A}), 107$ Stat. 312, 393.

160. The FCC found that SMR systems providing interconnected service should be classified as CMRS providers. Implementation of Sections $3(\mathrm{n})$ and 332 of the Communications Act; Regulatory Treatment of Mobile Services, 9 FCC Rcd. 1411, ๆा 90-92 (1994).

161. See 47 C.F.R. $\$ 24.301$ (2009).

162. ReEd Hundt, You Say You Want a ReVOlution 98 (1999).

163. CTIA, supra note 2. 
an estimated $\$ 22.2$ billion in $2009 .^{164}$ With licensees given wide latitude to choose the technologies deployed and the services offered, firms compete vigorously to improve services, upgrade architectures, cut prices, and provide popular platforms for third party content. Market forces compel efficiency of spectrum use in these bands. ${ }^{165}$

Wireless license auctions have likewise been a success. Since competitive bidding began in 1994, the government has realized $\$ 52.6$ billion in receipts. ${ }^{166}$ These numbers confirm the obvious: wireless service providers will pay substantial sums to avoid having to operate in a "spectrum commons." Any firm has the choice to do otherwise and deploy state-of-theart radios, spread spectrum devices, mesh Wi-Fi networks, or array antennae-all put forward as exhibits for the proposition that exclusive spectrum rights have outlived their usefulness. Yet, in March 2008, telecommunications firms shelled out $\$ 19$ billion to acquire exclusive access to $52 \mathrm{MHz}$ of prime frequencies-paying far higher prices than in previous FCC auctions on an adjusted "per MHz-pop" basis. ${ }^{167}$ That firms reject available "free" spectrum in unlicensed bands and instead bid aggressively to acquire liberal licenses suggests that firms expect exclusive spectrum ownership to offer productive efficiencies.

The standard explanation of private property rights in the economics literature is that a grant of exclusive control creates incentives for resource conservation and improvement. ${ }^{168}$ Liberal spectrum licenses promote precisely these outcomes. Between June 1985 and June 2009, cellular networks built approximately 241,000 cell sites, ${ }^{169}$ investing some $\$ 274$ billion

164. CEA Database, supra note 4.

165. Of course, this "property rights" framework is limited both in the extent of the liberalization and in its scope (i.e., allocated spectrum). See Kwerel \& Williams, supra note 8.

166. Press Release, Fed. Commc'ns Comm'n, Statement by FCC Chairman Kevin J. Martin (Mar. 18, 2008).

167. Price comparisons are generally made by adjusting for the bandwidth allocated the license $(\mathrm{MHz})$ and the population in the coverage area of the license (pop). The $700 \mathrm{MHz}$ auction brought an average winning bid of $\$ 1.20$ per $\mathrm{MHz}$-pop, while the 2006 AWS auction averaged 51 cents. The largest previous auction for broadband PCS licenses, in terms of bandwidth assigned, was the A-B auction concluded in March 1995. It generated total bids of $\$ 7.7$ billion and an average price equal to 51 cents per MHz-pop. Thomas W. Hazlett, David Porter \& Vernon Smith, Radio Spectrum and the Dismuptive Clarity of Ronald Coase, 54 J.L. \& ECON. (forthcoming Nov. 2011) (manuscript at v, 1), available at http://papers.ssrn.com/ sol3/papers.cfm?abstract_id=1583098; see also Jeremy Bulow, Jonathan Levin \& Paul Milgrom, Winning Play in Spectrum Auctions (NBER, Working Paper No. 14765, 2009), available at http://www.nber.org/papers/w14765.

168. See generally Demsetz, supra note 52.

169. CTIA, supra note 89. 
in the process. ${ }^{170}$ CMRS network and end-user equipment evolved rapidly, smoothly transitioning from analog to digital service. Advanced compression technologies and smart antennas have been widely deployed, allowing carriers to pack more and more traffic into given bandwidth. For example, CDMA handsets are programmed to check 800 times per second for the lowest possible power level that maintains a link to the base station; GSM over 1,000 times. Dynamic power adjustment reduces spillovers, allowing more phone calls to be made. ${ }^{171}$ These innovations and a host of others have resulted in increasingly intense use of frequency space. In its 2004 Comments to the FCC, CTIA noted: "[I]n 1993 a $10 \mathrm{~km}$ cell would have averaged fewer than seven subscribers per MHz. In 2003, in the same $10 \mathrm{~km}$ area, wireless averaged just under 500 subscribers per $\mathrm{MHz} .{ }^{, 172}$

\section{OVERLAYS}

Thus, over two decades, great progress has been made in creating exclusive, flexible-use, geographically defined spectrum licenses. CMRS operators have freedom to choose what kind of network equipment to deploy and what services to offer. The approach has also given rise to the regulatory innovation of "overlay" rights. Bands littered with incumbent users, but containing substantially under-utilized "white spaces," are shared with new, encumbered licenses. The new licensee can emit, with broad flexibility, in the allotted frequencies, while respecting the operations of existing users who are grandfathered to continue transmitting. Incumbents are free to "sell out" to the new licensee, moving operations to other bands, fixed links, or ceasing altogether, with the overlay licensee capturing the benefits created.

Overlays effectively cede the task of spectrum reallocation to markets, endowing the overlay licensee with property rights to the fruits of whatever new, innovative band uses it can create. For example, new PCS licensees relocated 4,500 microwave incumbents, paying their moving costs, in order to take full advantage of their spectrum. ${ }^{173}$ Likewise, in the $700 \mathrm{MHz}$ band, Qualcomm paid dozens of TV stations on Channels 54, 55, and 56 to accept interference so that Qualcomm's new mobile TV application, MediaFlo,

170. CTIA, CTIA's WIRELESS INDUSTRY INDICES 133, 153 (2009).

171. Time for Plan B, ECONOMIST (Sept. 26, 2002), http://www.economist.com/ business/displayStory.cfm?story_id=1353050 (discussing how to make 3G work in Europe).

172. Comments of Cellular Internet \& Telecomms. Ass'n at 5, Interference Temperature Metric, ET Docket No. 03-237 (Fed. Commc'ns Comm'n Apr. 5, 2004), available at http:// files.ctia.org/pdf/filings/ITEMPcomments.pdf.

173. Cramton, Kwerel \& Williams, supra note 32, at 668. 
could launch nationwide service in $2007 .{ }^{174}$ Similar overlays are also used in the AWS frequencies, where licenses were auctioned in $2006 .^{175}$

No alternative property regime allows such efficiencies. In unlicensed bands, the dealmakers necessary for efficient coordination do not exist, which is exactly why such "commons" must rely on spectrum allocations, power limits, and technology mandates pre-set by regulators. Commons advocates have argued that abundant economic unlicensed activity now takes place in what were formerly considered "junk" or "garbage bands," useless for productive activity. ${ }^{176}$ But liberally licensed bands have likewise often started with "garbage" and then struck gold by moving thousands of polluters out. The unlicensed bands host valuable applications, but only by powering down, accepting intermittent interference, and living amongst the "garbage." These constraints severely limit the potential of such bands and deter certain unlicensed frequencies, including those allocated to U-PCS and to the $3650-3700 \mathrm{MHz}$ band, from providing net social value. Hamstrung by FCC rules and assigned to no owner, these bands are stuck in the bowels of administrative process.

\section{FROM LMDS TO WIMAX, A REGULATORY ODYSSEY}

Consider the evolution of Wireless Metropolitan Area Networks ("WMANs"). These technologies support wireless links that can span distances of up to thirty miles; they can be used to backhaul traffic from local points of aggregation, or to provide last-mile broadband connectivity directly to customers. ${ }^{177}$ Both the first-generation WMAN technologies (LMDS and MMDS, for example) and the second (WiMax and Mobile Fi) were designed to operate principally in licensed bands. Unlicensed bands are viewed as viable alternatives only in sparsely populated, rural locations. The treatment of the rival spectrum models, both in regulatory proceedings and in the marketplace, evinces underlying realities about the scarcity of spectrum and socially useful methods to organize radio access.

174. Thomas W. Hazlett, A Law and Economics Approach to Spectrum Property Rights: $A$ Response to Weiser and Hatfield, 15 GEO. MASON L. REV. 975, 1000-04 (2008).

175. See, e.g., Marketing Materials, Comsearch, Spectrum Sharing and Incumbent Relocation Services for AWS Licensees (2009), available at http://docs.commscope.com/ Public/Spectrum_Sharing_and_Relocation.pdf.

176. Philip J. Weiser \& Dale N. Hatfield, Policing the Spectrum Commons, 74 FORDHAM L. REV. 663, 663 (2005).

177. FCC Task Force Paper, supra note 17, at 20 ("Wireless Metropolitan Area Networks (WMANs) are point-to-point or point-to-multipoint networks with individual links that not only can span distances of up to 30 miles, which is important for backhaul applications, but also can provide last-mile connectivity in metropolitan environments."). 


\section{A. EARLY WMAN INVESTMENTS AND THE EMERGENCE OF FIXED WIRELESS TECHNOLOGIES}

The first major wave of investment in WMAN technologies occurred shortly after passage of the Telecommunications Act of $1996 .{ }^{178}$ Between 1997 and 2000, the FCC licensed several large parcels of spectrum for these services-the $24 \mathrm{GHz}$ band allocated for Digital Electronic Messaging Service ("DEMS"), Distribution System, ${ }^{180}$ and the $39 \mathrm{GHz}$ band. ${ }^{181}$ These high frequencies provide very generous bandwidth, but signals carry only a couple of miles and require a clear line of sight. ${ }^{182}$ Companies like Teligent, WinStar, and NextLink (later XO) bid aggressively to acquire licenses. ${ }^{183}$ By year-end 2001 , these companies had spent over $\$ 10$ billion building out their networks. ${ }^{184}$ But the radios capable of handling these high frequencies were very

178. Pub. L. No. $104-104,110$ Stat. 56 (1996).

179. DEMS services were initially allocated spectrum in the $18 \mathrm{GHz}$ band. This allocation was then moved to a different section of the same $18 \mathrm{GHz}$ band. DEMS was finally relocated to the $24 \mathrm{GHz}$ band in 1997. See Amendments to Parts 1, 2, 87 and 101 of

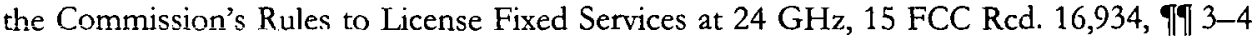
(2000).

180. See Factsheet for Auttion 17: Local Multipoint Distribution System (LMDS), FED. COMMC'NS COMM'N (Nov. 29, 2007), http://wireless.fcc.gov/auctions/default.htm? job=auction_factsheet\&id=17. There are two LMDS licenses issued in each of 493 Basic Trading Areas (BTAs). Frequency Block A licenses are for $1.15 \mathrm{GHz}$ in the $27.5-28.35 \mathrm{GHz}$, 29.1-29.25 GHz, and 31.075-31.225 GHz bands; Frequency Block B licenses are for 150 $\mathrm{MHz}$ in the $31-31.075 \mathrm{GHz}$ and $31.225-31.300 \mathrm{GHz}$ bands. Id.

181. See Factsheet for Auction 30 (39 GHz), FED. COMMC'NS COMM'N (July 27, 2006), http://wireless.fcc.gov/auctions/default.htm?job=auction_factsheet\&id=30 ("39 GHz licensees may provide fixed communications including point-to-point and point-tomultipoint communications.").

182. Presentation, K. Wanichkorn, Thailand Rural Wireless Broadband Access Initiative (APT Regional Forum for ICT Experts in South-East Asia, Feb. 4-5, 2004) (on file with authors) ("High Microwave Frequencies $(>10 \mathrm{GHz}$ )" work at "[s]hort propagation distances $(3-5 \mathrm{~km})$ and require line-of-sight"); Angela Langowski, LMDS Hits the Spot?, CED MAGAZINE, Feb. 1, 2001, available at http://www.cedmagazine.com/ced/2001/0201/id2. htm ("[LMDS] systems operate only over short distances.").

183. Langowski, supra note 182.

184. See, e.g., Neil Weinberg \& Michael Maiello, Malone Clone, ForbES (Apr. 15, 2002), http://www.forbes.com/forbes/2002/0415/082.html ("[Howard Jonas] bought Winstar Communications out of bankruptcy for $\$ 42$ million, gaining control of a broadband wireless network that had cost $\$ 5$ billion to build."); Jim Barthold, Teligent Faces New Sober Reality, CONNECTED PLANET (Sept. 16, 2002, 12:00 PM), http://connectedplanetonline. $\mathrm{com} / \mathrm{mag} /$ telecom_teligent_faces_new/ (quoting Teligent Marketing VP, Denisse Goldbarg, as saying, "We had $\$ 2$ billion to $\$ 3$ billion thrown at us."); Press Release, Infospace, Inc., Infospace Adds to Senior Management Team (Apr. 2, 2003), http://phx. corporate-ir.net/phoenix.zhtml?c $=119056 \& p=$ irol-newsArticle\&ID $=397450$ (noting that NEXTLINK raised more than $\$ 4$ billion in capital). 
expensive and much less reliable than wireline alternatives. ${ }^{185}$ These firstgeneration services all failed when Wall Street's dot-com bubble collapsed. ${ }^{186}$

As markets recovered and technologies for utilizing these bands improved, ${ }^{187}$ the licenses returned to investors' radar screens. ${ }^{188}$ Firms with new business models acquired the licenses in the 24, 27-31, and $39 \mathrm{GHz}$ bands. Companies like First Avenue Networks ${ }^{189}$ and IDT $^{190}$ began leasing this spectrum wholesale to providers of high-speed internet access, mobile carriers providing backhaul services, and wireline carriers building wireless extensions to their fiber-optic networks. This reallocation of spectrum to new and hopefully more valuable employments is an automatic function of exclusive rights, even through the disruption of bankruptcy. Indeed, trial and error is a socially useful discovery process when incentives guide investors to place the best bets, generating "creative destruction" that iterates on new efficiencies and produces technological disruptions of its own.

185. See, e.g., Intel and Cleanvire Forge WiMAX Alliance, THE REGISTER (Oct. 29, 2004, 11:08 AM), http://www.theregister.co.uk/2004/10/29/intel_clearwire_wimax/ ("The most critical element in the bursting of the last BWA bubble was the cost of subscriber equipment.... [T] he critical stumbling block for Winstar [was] the expensive, proprietary subscriber equipment.").

186. M. MCCormack \& Phil Cusick, Bear Stearns, Wireless Broadband: The IMPACT OF 802 TECHNOLOGY 17, ex. 7 (June 2004) (on file with authors).

187. Id. at 25 (noting that prices for $\mathrm{CPE}$ are still high, but "[t]he consensus from our interviews is that prices will be halved over the next two years, reaching a $\$ 100$ price point within five years"); $i d$. at 26 (remarking that the current generation of wireless broadband equipment is "greatly improved over equipment from the 1990s").

188. See, e.g., Press Release, First Ave. Networks, First Avenue Networks Closes Acquisition of Teligent Assets, PR NEWSWIRE (Jan. 18, 2005), http://www.thefreelibrary. $\mathrm{com} /$ First + Avenue +Networks +Closes + Acquisition + of +Teligent + Assets.a0132593914; M. Dano, Nextel Adds to MMDS Spectrum, RCR WIRELESS NEWS (Nov. 10, 2003, 6:00 AM), http://www.rcrwireless.com/article/20031110/SUB/311100739/-1/nextel-adds-to-mmdsspectrum. In 2006, First Avenue was acquired by FiberTower. Press Release, First Ave. Networks, Fiber'Tower Corporation and First Avenue Networks Announce Merger Agreement (May 15, 2006), http://www.fibertower.com/corp/downloads/investors/FT_ FAN_Release.pdf.

189. See Press Release, Covad, First Avenue Networks and Covad Announce Metro Wireless Reseller Agreement June 5, 2006), http://www.covadwireless.com/pdf_files/06_ 05_06_FirstAveNetworks.pdf ("First Avenue provides wireless backhaul and Carrier Ethernet services over its licensed spectrum footprint, which includes nationwide $24 \mathrm{GHz}$ and $39 \mathrm{GHz}$ holdings."); Press Release, IDT Corp., IDT Spectrum, Inc. Names Peter B. Atwal, President, Engineering and Operations (Apr. 28, 2005), http://www.idt.net/about/ press/story.aspx?id=9336 ("IDT Spectrum, Inc. is the recently formed subsidiary of IDT Corporation that operates and markets wireless spectrum products and solutions.").

190. Press Release, IDT Corp., IDT Corp. Announces the Acquisition of Winstar Communications, Inc. (Dec. 20, 2001), http://www.idteurope.com/corporate/press/ releases/246.asp. 
A new family of fixed wireless technologies-commonly known as WiMax-emerged in parallel. The original WiMax standard (IEEE 802.16) was developed to operate in licensed bands between 10 and $66 \mathrm{GHz}{ }^{19}$ Recent versions of the standard support both licensed and unlicensed operations between 2 and $11 \mathrm{GHz},{ }^{192}$ including licensed bands at $2.5 \mathrm{GHz}$ and $3.5 \mathrm{GHz}$, and the unlicensed $5.8 \mathrm{GHz}$ band that Wi-Fi radios often use. $^{193}$

Operators that will use licensed spectrum, however, dominate the new investment; equipment manufacturers and service providers have both concluded that this is where the most promising opportunities lie. Clearwire has aggregated licenses in the $2.5 \mathrm{GHz}$ band pursuant to a series of FCC rulings expanding licensee rights to allow two-way, cellularized, broadband services. ${ }^{194}$ By year-end 2010, it was offering wireless broadband service in at least sixty-eight markets, including Anchorage, Jacksonville, Waco, Reno, and Rochester, New York, ${ }^{195}$ and deploying $4 \mathrm{G}$ networks in New York City, Seattle, Washington, D.C., Los Angeles, Cleveland, and Cincinnati, among other cities. ${ }^{196}$ And it served 4.4 million subscribers, ${ }^{197}$ at least 100 times any WISP relying on access to unlicensed airwaves. ${ }^{198}$

191. Roger Marks et al., IEEE 802.16 Backgrounder, IEEE (May 24, 2002), http:// ieee802.org/16/pub/backgrounder.html.

192. Id.

193. See Intel, Understanding Wi-Fi and WiMAX as Metro-Access Solutions 10 (2004), http://www.rclient.com/PDFs/IntelPaper.pdf.

194. For the long regulatory history of $2.5 \mathrm{GHz}$ licenses, see Hazlett, supra note 28.

195. See Clearwire Markets, CLEARWIRE CORP., http://media.corporate-ir.net/media files/irol/21/214419/mediakit/Market_List_12309.pdf (last visited May 3, 2011).

196. Don Reisinger, Clearwire Extends $4 G$ Rollout to Five More Markets, CNET NEws (Nov. 29, 2010), http://news.cnet.com/8301-13506_3-20023955-17.html.

197. Dan Meyer, Cleanvire Posts Strong 4Q Wholesale Growth, Cost Conservation Remains Intact, RCR WIRELESS NEWS (Feb. 17, 2011), available at http://www.rcrwireless.com/article/ 20110217/CARRIERS/110219933/1097.

198. In its last ranking of Top Wireless ISPs, Broadband Wireless Exchange Magazine listed SpeedNet the third largest WISP with 15,000 customers. The two higher ranking ISPs (one of which was Clearwire) both use licensed spectrum in the $2.5 \mathrm{GHz}$ band; it was not specified whether SpeedNet used licensed, unlicensed, or both. See "Top Ten" Wireless Intermet Service Providers, BROADBAND WIRELESS EXCH. MAGAZINE (2007), http://www. bbwexchange.com/wireless_isp/; Kenyon Commc'ns Holdings, Inc., Quarterly Report (Form 10-Q), at 13 (June 30, 2009). 


\section{CARRIERS ADVOCATE FOR WIMAX}

Carriers that have used unlicensed spectrum have done so predominantly in rural areas. ${ }^{199}$ Intel, often a strong advocate of unlicensed spectrum, has concluded that, to supply "carrier class QoS [Quality of Service]," WiMax requires licensed spectrum. ${ }^{200}$ "In general," Intel concluded, "unlicensed bands can be subject to [service quality] issues because deployment is open to anyone." 201 In a 2007 paper, Intel outlined the differences between Wi-Fi and WiMax this way:

Licensed to Thrill. ... Unlicensed spectrum is open to any users, which raises the possibility of interference from other devices. WiFi networks use unlicensed spectrum. Wimax service providers use licensed spectrum which allows exclusive rights to its use for more predictability and stability. ${ }^{202}$

These very factors are what yield incentives for firms to sink substantial capital in creating spectrum complements-namely, wide area wireless networks. Clearwire itself began, in 1999, as a WISP operating "in the unlicensed $2.4 \mathrm{GHz}$ frequency, which was subject to interference." It found that it could lease licensed bandwidth from educational institutions with Instructional Television Fixed Service ("ITFS") licenses, upgrading its service and allowing it to craft an ambitious service strategy. ${ }^{203}$ Liberalization of the rights permitted in the ITFS licenses made this set of transactions possible. ${ }^{204}$

In that pursuit Clearwire has attracted powerful economic support, registering over $\$ 4$ billion in capital infusions from Intel, Motorola, Bell Canada, Google, Sprint, Comcast, Time Warner, Bright House Networks, and thousands of equity investors buying the firm's shares in its 2007 IPO. ${ }^{205}$ The financial meltdown of 2008-2009 adversely impacted share prices; much

199. See Intel Corp., DePloying LiCENSE-EXEMPT WiMAX SOlutions 6 (2005), available at http://empoweringsoho.flles.wordpress.com/2007/07/deployingwimaxlicense exemptband.pdf (" $[\mathrm{L}]$ icense-exempt WiMAX solutions are focused on rural areas . . ..").

200. Id. at 6-7; see also MCCORMACK \& CUSICK, supra note 186, at 8 ("In our view, the use of licensed spectrum is necessary to guarantee a level of service and availability for the paying portable user. The use of unlicensed spectrum could lead to wide disparities in quality of service, bottlenecks, and security issues.").

201. Intel, supra note 193 , at 3 .

202. Intel Corp., Welcome to Your Internet Future 15 (2007), http://download.intel.com/ network/connectivity/products/wireless/welcome-to-your-internet-future.pdf.

203. Cleanvire, Inc., FUNDING UNIVERSE, http://www.fundinguniverse.com/companyhistories/Clearwire-Inc-Company-History.html (last visited Jan 21, 2011).

204. See generally Hazlett, supra note 28.

205. Id. at 256. 
of Clearwire's strategic investment was written off in early $2009 .{ }^{206}$ This is entirely consistent with the social efficiencies created by such investment incentives. Only when firms suffer the adverse consequences of the risks they take will their incentives be fully aligned with the interests of consumers. When, conversely, Apple Computer lobbied the FCC for an U-PCS frequency allocation in the early 1990s, prompting the Commission to allocate $30 \mathrm{MHz}$ for U-PCS that has gone essentially unused for over a decade, the loss was socialized. Apple internalized only the cost of its lobbying. ${ }^{207}$

\section{FCC'S REgULATION VIA REgISTRATION HAS CREATED INEFFICIENCIES THAT LIBERAL LICENSES WOULD NOT}

The FCC's recent proceeding to allocate the $3.65 \mathrm{GHz}$ band for nonexclusive access rights was initiated at the behest of wireless WISPs who "expressed a clear need for additional spectrum for broadband use... especially in rural areas." 208 The FCC was persuaded, stating that allocating the band for unlicensed devices "would be the most beneficial approach." ${ }^{209}$ Still, rural WISPs were concerned that "intense use of spectrum by a variety of devices under a traditional unlicensed approach could result in mutual interference, thereby reducing the utility of this band." ${ }^{210}$ In 2005 , the Commission ultimately adopted a regime that eschews assigning any spectrum "for the exclusive use of any licensee"211 and instead directs all licensees "to cooperate and avoid harmful interference to one another.",212

206. See, e.g., Stacey Higginbotham, Intel Writes Almost \$1B Off Cleanvire Investment, GIGA OM (Jan. 7, 2009), http://gigaom.com/2009/01/07/intel-writes-almost-1b-off-clearwireinvestment/. Overall, capital losses are approximated by comparing the capitalization estimated by Wall Street analysts when the company was acquiring investment partners (and public investors in an IPO), to the current enterprise value. The former valuation was $\$ 14.5$ billion, the latter is $\$ 3.5$ billion. Erick Schonfeld, $\$ 3.2$ Billion Wimax Deal Goes Tbrough. Take Cover, TECHCRUNCH (May 6, 2008), http://techcrunch.com/2008/05/06/32-billion-wimaxdeal-goes-through-take-cover/; Key Statistics for Clearvire (CLWR), YAHOO! FINANCE, http:// finance.yahoo.com $/ \mathrm{q} / \mathrm{ks}$ ? $\mathrm{s}=\mathrm{CLWR}+$ Key + Statistics (last visited Feb. 27, 2011) (listing enterprise value at $\$ 3.54$ billion as of Feb. 27, 2011).

207. Thomas W. Hazlett, The Spectrum-Allocation Debate: An Analysis, 10 IEEE INTERNET Computing 68, 73-74 (Sept.-Oct. 2006).

208. Wireless Operations in the 3650-3700 MHz Band, 20 FCC Rcd. 6502, ๆ 13 (2005).

209. Id.

210. Id. $ๆ 14$.

211. Id. app. A.

212. Id. 16. All licensees are required "to cooperate and avoid harmful interference to one another." Id. All WiMAX radios must incorporate protocols to determine who gets priority when "when two or more devices attempt to simultaneously access the same channel." Id. These same protocols will "establish[] rules by which each device is provided a 
Everyone operating in these bands must register "their fixed and base stations in a common database." ${ }^{213}$ And any interference between these highpower transmitters "will be addressed by the process we adopt to register fixed and base stations." 214 Registration rules require base stations to "operate at locations and with technical parameters that will minimize the potential for interference between stations." 215

The better this registration policy works in the short term, the faster its fundamental shortcomings will become apparent. Many companies certainly want to offer WiMax service, competing in the $\$ 32$ billion per year U.S. market for DSL and cable modem services. ${ }^{216}$ Spectrum-sharing protocols in WiMax radios can provide for orderly, reasonable sharing of spectrum, under certain circumstances. But they do not limit how many radios are deployed to share it.

Just as power limits are an implicit exclusionary device, a registration policy is likewise an acknowledgement of the benefits of coordinating spectrum users and a rejection of "open access." The unlicensed space is in some sense licensed, but without the benefit of de facto (or de jure) spectrum ownership. Under this hybrid approach, there are no claimants to seek gains from efficient spectrum reallocation-for example, to clear the $3650 \mathrm{MHz}$ band of the satellite operations that could impinge on the use of WiMax devices. In a liberal license regime, licensees could pay satellite operators to move to alternative bands, thus expanding opportunities for WiMax. Under the hybrid approach, it is regulators, not market forces, that set sharing rules.

What advantage does such state control afford society? The reflex response-that it protects spectrum access on a no-fee basis-is strictly correct. But this regime can render "free" access a high-cost failure. If the coordination supplied by exclusive rights owners results in networks and applications that are superior from the viewpoint of consumers, but fail to materialize here, then the incremental social benefits of the non-exclusive rights are negative.

U.S. regulators, as Coase deduced from basic economic theory, fail to properly account for the opportunity costs of alternative allocations when

reasonable opportunity to operate." Id. By "control[ling] access to spectrum, terrestrial operations will avoid interference that could result from co-frequency operations." Id.

213. Id.

214. Id.

215. Id.

216. Ray Le Maistre, US Tops Broadband Revenues Chart, LIGHT READING Jan. 2, 2009), http://www.lightreading.com/document.asp?doc_id=169812 ("According to data compiled for the report, Global Fixed and Mobile Broadband Outlook, the United States generated more than $\$ 32$ billion in broadband revenues in 2008."). 
zoning spectrum. The results are starkly on display in the $3650 \mathrm{MHz}$ proceeding. What is called the $3.5 \mathrm{GHz}$ band includes the $3650-3700 \mathrm{MHz}$ frequencies; it is the most popular location for licensed WiMax networks internationally. ${ }^{217}$ Indeed, the IEEE 802.16 (WiMax) technology protocol at $3.5 \mathrm{GHz}$ has been written for exclusive rights holders. U.S. regulators chose to deviate from world markets, a decision strongly opposed by Intel and Alvarion, firms with substantial sales of wireless hardware using the $2.4 \mathrm{GHz}$ and $5 \mathrm{GHz}$ unlicensed bands. Yet, the companies jointly urged the FCC to license $3650 \mathrm{MHz}$ spectrum in the top fifty U.S. markets-areas with the lion's share of potential customers and those in which potential airwave conflicts are most intense. ${ }^{218}$ They lost that battle, ${ }^{219}$ and the only large-scale WiMax developments observed in the U.S. market today are those in the licensed $2.5 \mathrm{GHz}$ band.

\section{THE QUIET PAST AND THE NOISY FUTURE}

There was no demand for spectrum before 1895 because nobody yet knew how to build a radio. Guglielmo Marconi demonstrated the basic engineering that year, but it would take another thirty years to develop products and business models to move hundreds of broadcast stations and millions of receivers into the mass market - enough radio hardware to spawn the conflicts that impelled the creation of a legal regime to police spectrum access. $^{220}$

To frame this history in terms relevant to the current debate, licenses matter when radio technologies and markets evolve to the point where things get crowded. The commons advocates insist that when the technology is smart enough, things never get crowded. That story is exactly backwards. Setting aside regulatory barriers, it is the lack of technology that has left some bands relatively empty. Bands that were empty a decade ago are crowded today in large measure because affordable new products have arrived to fill them. In our frame of experience, technology is not the solution to spectrum scarcity, but its cause. As wireless technologies become smart, cheap, and

217. Sam Churchill, Italy Opens 3.5 GHz for WiMax, DAILY WIRELESS (Dec. 29, 2006, 10:07 AM), http://www.dailywireless.org/2006/12/29/italy-opens-35-ghz-for-wimax/.

218. Petition of Intel Corp. et al., Petition for Reconsideration of Intel Corporation, Redline Communications, Inc., Alvarion, Inc., ET Docket No. 04-151 (Fed. Comm'ns Comm'n June 10, 2005) (arguing that the FCC's refusal to license $3650 \mathrm{MHz}$ spectrum would lead to squatting, inefficiency, and delay).

219. Jerry Brito, The Spectrum Commons in Theory and Practice, 2007 STAN. TECH. L. REV. 1, IT 75-78.

220. On the origins of these conflicts and the policy course taken, see Hazlett, supra note 121. 
ubiquitous, the social value of property rights--helping to create the platforms on which such burgeoning economic activity can be best accommodated-rises.

We face a world of spectrum scarcity looking forward. A radio's power amplifier is the toughest part to build, and the higher the frequency, the tougher it gets. Twenty years ago, no one knew how to build the highfrequency gallium arsenide chip-scale amplifiers that now power many Wi-Fi radios. Wi-Fi radios operate at 2.4 and $5 \mathrm{GHz}$, and cheap, compact chip-scale amplifiers capable of handling such high frequencies had not been developed until around that time. Military research funded the development of this exotic semiconductor, ${ }^{221}$ and licensed wireless carriers created the massmarket demand by selling millions of cell phones. ${ }^{222}$ In that sense, Wi-Fi took a free ride on technological innovation in licensed bands.

Unsurprisingly, the history of FCC licensing has tracked the progressive march of radio-amplifier technology up the frequency ladder-albeit with significant, wealth-destroying lags. ${ }^{223}$ And the FCC's allocation of spectrum for mass-market licensed services has largely tracked the frequency-climbing evolution of radios. ${ }^{224}$ The amount of usable spectrum continues to expand because engineers continue to push radio frequencies up into higher bands, and radio costs down. The spectrum always looks uncrowded to pioneers at the very top of the ladder. Then, when costs drop and regulatory barriers fall, crowds follow.

221. See Press Release, TRW, TRW To Fabricate Advanced Integrated Circuits for RF Micro Devices (Dec. 7, 1993) ("Much of TRW's [gallium arsenide (GaAs)] chip manufacturing expertise was developed as part of the Microwave and Millimeter Wave Monolithic Integrated Circuits (MIMIC) program sponsored by the Department of Defense's Advanced Research Projects Agency (ARPA).... The MIMIC program was begun in 1987 by ARPA to make GaAs integrated circuits producible, affordable and applicable to a wide range of critical defense system needs.").

222. See, e.g., Tim Whitaker, SiGe and CMOS Target GaAs Dominance of Cellular PA Slots, COMPOUND SEMICONDUCTOR (May 4, 2004), http://compoundsemiconductor.net/csc/ features-details.php?id=19397 ("II]n the largest market segment, [power amplifiers] for cellular handsets, GaAs enjoys almost total dominance, and accounted for well over $95 \%$ of handset [power amplifier] revenues [in 2003], according to market research firm ABI Research.").

223. Cellular phone allocations were delayed from the late 1940s, when cellular technology was developed by Bell Labs, until licenses were distributed in the 1980s-one notable example of regulatory lag. See GeOrge CalHoun, Digital Cellular Radio 3949 (1988).

224. See infra Figure 2. 
Figure 2: Progressive Allocation of Spectrum for

Commercial Mass-Market Wireless Services

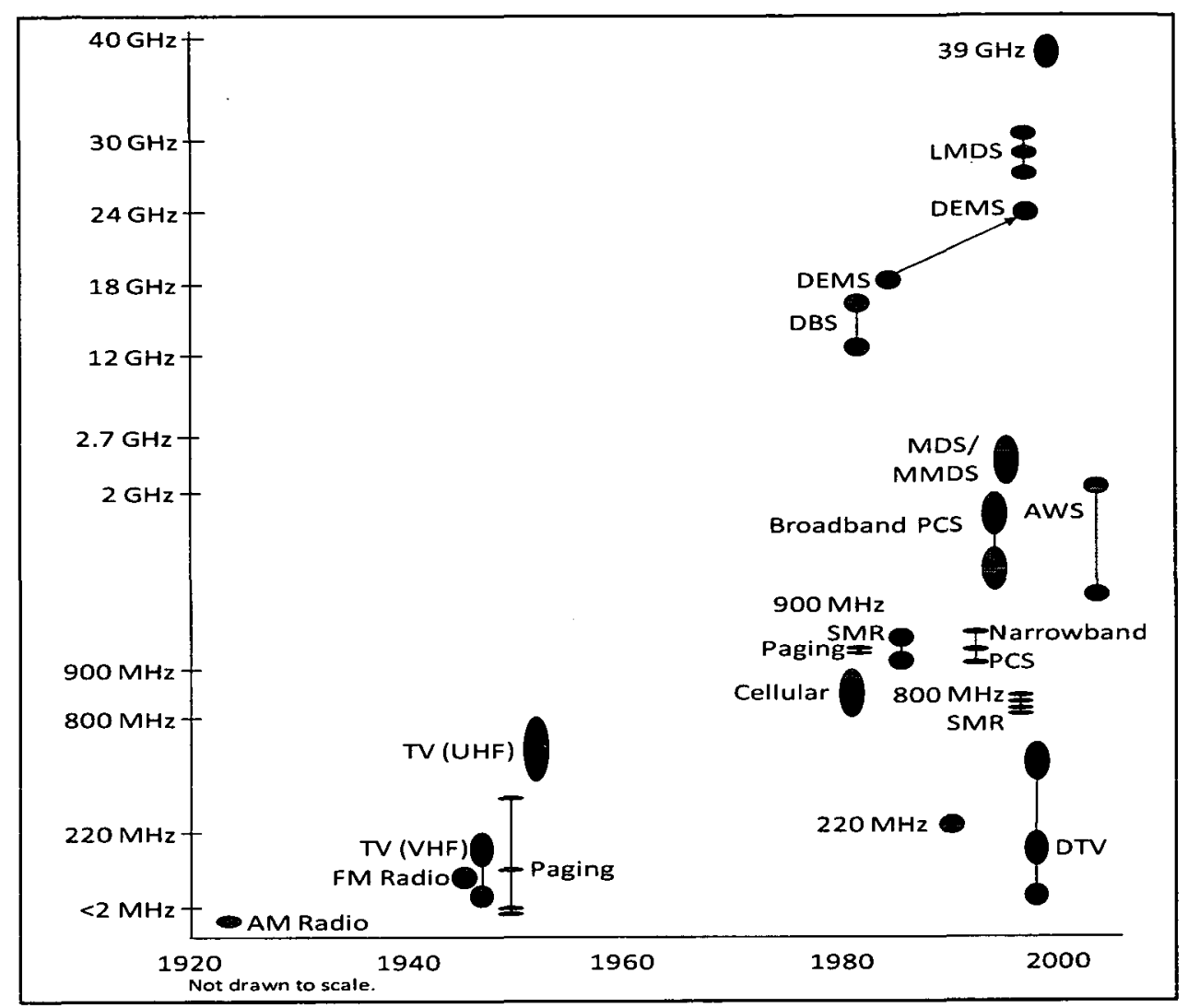

The bands occupied today have an additional feature: many highfrequency transmissions are easily blocked by physical obstacles, rain, and so forth. DBS satellites, for example, broadcast at $12 \mathrm{GHz}$. At this frequency, signals are blocked by foliage, so that pizza-sized receiving antennas require a treeless line of sight to the southern sky. Heavy rain can also block these signals. By contrast, the Navy's ultra-low-frequency radios can communicate with submerged submarines. That high-frequency signals are easily blocked is a schizophrenic blessing, as the Wi-Fi experience again teaches. One Wi-Fi radio is unlikely to interfere with another when shielding supplied by walls or windows sharply limits its range. But that same limit is what makes it relatively costly to scale Wi-Fi deployments for many applications larger than a Starbucks.

\section{A. CONFLicts in Radio COMmUnications}

Smart radios have overcome the problem of interference, commons advocates allege. Unlicensed wireless devices may not have legal protection against interference, but they do not need any. It is possible that licensing 
spectrum may occasionally be useful, just as "toll roads or paid carpool lanes" sometimes make sense "in some predictably congestion-prone roads." ${ }^{\text {"25 }}$ But mostly we are dealing here with "city streets and sidewalks, dirt roads, or highways at nighttime." 226 Smart radios are like ships traveling on an ocean of spectrum-not infinite in size, perhaps, but so vast that vessels can simply "be trusted to navigate around one another.",227

These conclusions are said to flow from the laws of physics: "[I]nterference is a consequence of system design, rather than an inherent property of the radio spectrum.",228 Interference is not "physical" but "inherently a legal construct." 229 "Interference is a metaphor that paints an old limitation of technology as a fact of nature."230 "Spectrum is not scarce. We're talking about radio waves. Radio waves run through one another."231 "More than one service can occupy the 'same' spectrum, in the same place, at the same time." "232 "The electromagnetic waves do not actually bounce off each other or 'fall' to the ground before reaching the receiver's antenna. 'Interference' describes the condition of a stupid lone receiver faced with multiple sources of radiation that it is trying to decode but, in its simplicity, cannot." "233 "Radio waves do not . . cancel each other out." ${ }^{, 234}$

But, in fact, they do.

\section{Noise and Interference}

Thomas Young's double slit experiment, first conducted in 1801 and repeated in high-school physics classes to this day, establishes that electromagnetic waves interact, interfere, amplify, and obliterate each other like waves on the surface of a pond. Two clean signals superposed become one messy one; throw in more and you end up with a cacophony of pure

225. Benkler, supra note 17 , at 69 .

226. Id. at $69,32-33$ (stating that property rights and pricing mechanisms are "useful only occasionally, at peak utilization moments").

227. WERBACH, supra note 17, at 20.

228. Id. at 14 .

229. Id.

230. David Weinberger, The Myth of Interference, SALON (Mar. 12, 2003), http://dir.salon. $\mathrm{com} /$ story/tech/feature/2003/03/12/spectrum/index.html? (quoting David Reed).

231. Heath Row, The Open Spectrum Revolution, FAST COMPANY (Mar. 13, 2004), http://www.fa'stcompany.com/blog/heath-row/open-spectrum-revolution (quoting Kevin Werbach).

232. WERBACH, supra note 17 , at 3 .

233. Benkler, supra note 17 , at 39 .

234. WERBACH, supra note 17 , at 5. 
noise. No amount of additional intelligence embedded in the receiver can reverse the process when interference transforms information into chaos. ${ }^{235}$

In fact, radios dispatch streams of energy from their antennas, and that energy propagates through the surroundings at the speed of light. These fluxes are not legal constructs, ${ }^{236}$ but physical things. In a microwave oven, they heat soup. When they strike a silicon-crystal solar cell, electromagnetic energy at a slightly higher frequency can generate electricity. Suitably synchronized, flukes like these become a maser or laser that can cut through steel. And these same energy fluxes - streams of photons of dual wave-like and particle-like nature-interact, deflecting flows and destroying communications.

Thus, for example, microwave ovens cause "noticeable" interference with Bluetooth devices operating nearby. ${ }^{237}$ Bluetooth devices interfere with each other. ${ }^{238}$ Cell phone jammers are readily available (though illegal ${ }^{239}$ ); it is equally easy to jam Wi-Fi nodes. The most common form of interference

235. The concession is made that interference among smart radios is a "realistic possibility" when "very large numbers of such devices operate in the same location." Id. at 17. That this obviates the claim that interference is a myth, or that it fully supports the economic analysis of spectrum scarcity is, however, lost.

236. Were radio signals "only" legal constructs, the argument over how best to assign property rights would not be decided, of course. Intangible property rights, including those created in contract law, tend to dominate ownership institutions in advanced economies. More generally, all property rights are legal constructs and govern not things but relations between people.

237. T.W. Rondeau, M.F. D'Souza \& D.G. Sweeney, Residential Microwave Oven Interference on Bluetooth Data Performance, 50 IEEE TRANSACTIONS ON CONSUMER ElECS. 856, 863 (2004).

238. J.E. Ballagh, T.W. Rondeau \& D.G. Sweeney, Bluetooth Frequency Hop Selection Kermel Impact on Inter-Piconet' Interference, IEEE TRANSACTIONS ON CONSUMER ELECS. (forthcoming); see also J. Lipman, The "Otber" Wireless Tecbnology Is Alive and Kicking, EE TIMES (Oct. 14, 2003), http://www.techonline.com/community/ed_resource/feature_article/ 28419 (" $\mathrm{S}$ ]imilar to devices operating in the $900 \mathrm{MHz}$ spectrum interfering with other likefrequency devices, Bluetooth is more prone to interference from other Bluetooth devices, cell phones, microwave ovens, and other equipment operating at $2.4 \mathrm{GHz}$.'); Jonathan Miller, Tips on Using WiFi in RV Parks, RVERS ONLINE (Mar. 2005), http://www. rversonline.org/RVWiFi.html ("From 4:30 to $6: 00$ pm each night at every RV resort in the country the WiFi signal is impeded the most. This is due to the concentration of RVs in a relatively small area preparing dinner and using Microwave ovens. The same is true in apartment complexes.").

239. The manufacture, importation, sale, and operation of transmitters designed to jam or block signals is a violation of 47 U.S.C. $\int \$ 301,302(a), 333(2006)$, and is subject to severe penalties. "Fines for a first offense can range as high as $\$ 11,000$ for each violation or imprisonment for up to one year." Cellular Services, Operations: Blocking \& Jamming, FED. COMMC'NS COMM'N, http://wireless.fcc.gov/services/cellular/operations/blockingjamming. html (last updated Nov. 19, 2002). 
arises when an emission from a single transmitter interferes with itself. This can occur when part of a signal travels directly from the tower to the television, and part travels indirectly, reflecting off (say) a nearby skyscraper. Two different electromagnetic signals of the same frequency cannot in fact coexist at exactly the same place and time.

All else equal, the noisier the electromagnetic environment, the longer it takes to transmit information through it without distortion. This too is a fundamental law of physics ${ }^{240}$ that engineering cannot repeal. To state the same law another way: to get through at all, a radio transmission has to be powerful enough to penetrate the ambient noise.

The "ambient noise" itself is highly variable. It is composed of all the radio transmitters-"intentional emitters," in FCC jargon-and all the "incidental" and "unintentional" emitters, including virtually every device that runs on $\mathrm{AC}$ electric power. It is therefore impossible to know precisely how noisy things will be along any given pathway, at any given point in time; getting a signal through is a fundamentally chancy business. ${ }^{241}$ One can improve the odds of getting a signal through by raising the power of one's radio, or lowering the power of other radios transmitting on the same frequencies, or shutting down competing radios altogether. One can switch one's radio to a different band, which may be quieter. And one can transmit the same message more than once, or simultaneously on multiple bands.

But none of these strategies eliminates fundamental economic trade-offs. Quite the contrary-every strategy that boosts the chances of punching your own signal through the airwaves either adds to the expense of the communications conducted, lowers the odds for every other radio that is trying to do the same, or both. It is suggested that by searching for unused gaps in the airwaves, "agile radios can in effect manufacture new spectrum."242 "In effect," correct, but in fact radios transmit radio signals, and when they do that, they do not produce spectrum, they consume it.

The much-heralded smartness of Wi-Fi radios provides a case in point. When two Wi-Fi radios use the same (limited) channels in close proximity, each device detects the presence of a competing transmitter and adjusts by transmitting more slowly and using more power to send each bit. As Hewlett-Packard describes it, Wi-Fi radios "fail gracefully in the presence of interference"- the "result of increasing levels of interference is almost

240. See C.E. Shannon, A Mathematical Theory of Communication, 27 BELL SYS. TECH. J. 379 (1948), available at http://www.alcatel-lucent.com/bstj/vol27-1948/articles/bstj27-379. pdf.

241. Weiser \& Hatfield, supra note 176.

242. WERBACH, supra note 17 , at 19 (emphasis added). 
always confined to a slowing of the data rate as more packets need to be present." 243 Wi-Fi does not eliminate the interference problem but degrades performance to accommodate it. This is more acceptable for certain types of data transmission where it does not matter too much how fast the traffic gets through, such as web browsing, while it is less acceptable for voice and other interactive applications that require steady throughput.

These limitations are costly. Moreover, the coordination between users that may mitigate these costs is difficult to achieve. Wi-Fi radio users, particularly those who attempt outdoor deployments, are advised to seek out other Wi-Fi users and gain their cooperation, using different channels and placing facilities in complementary locations. ${ }^{244}$ Indeed, WISPs may find themselves in "broadcast wars," where transmissions to occupy Wi-Fi channels, along with the use of higher power levels, are strategic tools used to lower rivals' quality of service. ${ }^{245}$ Degraded performance is only the tip of the iceberg; networks never deployed due to the costs of coordination in this space constitute the largest losses. The tragedy of the commons is the unobserved counter-factual.

\section{Pbysics and Architecture}

Radio waves are real things transmitted with real energy. ${ }^{246}$ Potential conflicts depend on the separation, if any, between the band being used by the interfering transmitter, and the band that the unwitting receiver is trying to decipher. It depends on the power of the rival transmitter, its proximity,

243. HEWLETT-PACKARD, WI-FI AND BLUETOOTH-INTERFERENCE ISSUES 1 (2002), available at http://www.hp.com/rnd/library/pdf/WiFi_Bluetooth_coexistance.pdf.

244. Tim Pozar, Regulations Affecting 802.11 Deployments, Version 1.5 (Mar. 10, 2004) (unpublished manuscript), available at http://www.lns.com/papers/part15/Regulations_ Affecting_802_11.pdf.

245. Christian Sandvig, The Return of the Broadcast War 23 (Sept. 23, 2005) (unpublished manuscript), available at http://www.communication.illinois.edu/csandvig/ research/Broadcast_War.pdf (quoting one WISP operator as saying, "The more channels I grab means the less competition").

246. Although the concepts are often used interchangeably, it is here important to distinguish between "spectrum," which itself is not a physical thing, and the radio waves or signals that are transmitted through space. See Howard A. Shelanski \& Peter W. Huber, Administrative Creation of Property Rights to Radio Spectrum, 41 J.L. \& ECON. 581, 584 (1998) ("There is no such thing as 'spectrum' out there, any more so than there was 'ether,' to be bottled by the Commission or anyone else. 'Spectrum' is composed entirely of the engineering characteristics of transmitters and receivers. Those characteristics are defined, in turn, by power, sensitivity, and modulation parameters in a fuzzy and permeable zone of space."). Thus, when we talk about the scarcity of spectrum, this is shorthand for the conflicts resulting from the transmission of radio waves within defined frequency spaces. 
and on directional antennas mounted (or not mounted) on the transmitter, the unwitting receiver, or both.

The interference problem is defined by the aggregate of all competing transmitters, i.e., by the transmission frequencies, power, proximity, and antenna configurations of all intentional, incidental, and unintentional interfering transmitters in the band, and all the buildings, foliage, fog, meteor trails, and extraterrestrial radiation belts, that may reflect their signals (usually aggravating the problem) or attenuate them (usually mitigating it). A licensee with liberal spectrum rights uniquely possesses the information, economic incentive, and financial ability to optimize the architecture to make the best possible use of such a complex, turbulent resource.

As Ronald Coase noted decades ago, the appropriate quest is not to eliminate interference between wireless users, which is overly protective, but to achieve just the proper amount. ${ }^{247}$ How much interference is tolerable can never be defined by the interfering transmitter-it must, self-evidently, be defined by the receiver. Firefighters groping their way through an inferno tolerate less interference than teenagers text-messaging at the mall. "Tolerable" itself is inevitably defined in statistical terms: how often will noise levels rise high enough to block a transmission, and what blocking probability is acceptable given the cost of reducing the odds?

The argument that radio waves do not interfere, that spectrum is not scarce, implies that the only quality of service issue lies in the design of the individual receiver. A race for better radios then becomes the alternative to network coordination. ${ }^{248}$ When interference is explained as a problem of insufficient processing power in the radio receiver, individual users are portrayed as efficiently pursuing - with help from equipment vendors, who profit from selling better radios-the optimal level of reception (the reciprocal of interference).

This mischaracterizes the economic problem, which centers on how to entice all productive contributions where benefits exceed costs. Whatever the incentive of an individual to buy a radio that punches through the din, and the vendor to profit from selling that device, the resulting transactions will not take account of the costs transmissions impose on other users. This loads all interference mitigation on the individual user's radio and government rules (such as power limits), with decisions taken in isolation from other sources of conflict. While mobile carriers, as spectrum owners, aggressively

247. "It is sometimes implied that the aim of regulation in the radio industry should be to minimize interference. But this would be wrong. The aim should be to maximize output." Coase, supra note 21, at 27.

248. See WERBACH, supra note 17, at 37; Benkler, supra note 17. 
deploy systems that make radios quieter and spillovers smaller, unlicensed device users predictably pollute the airwaves by blasting signals at higher power than necessary so as to guarantee safe passage for their communications. ${ }^{249}$ In short, each user competes to claim control over airspace, insensitive to the costs imposed on others. This is standard tragedy of the commons, ${ }^{250}$ and there is considerable concern among engineers about how to deter it in unlicensed bands. ${ }^{251}$ This inevitably involves some level of enhanced coordination, public or private. ${ }^{252}$

249. Radio engineers who work with Wi-Fi commonly acknowledge costs of nonexclusivity. Using $5.8 \mathrm{GHz}$ frequencies to bring broadband connections to a housing development in a low-income part of San Francisco, Tim Pozar notes that "[f]requency coordination is a constant problem," as new radios distupt existing links and there is "no way to encourage or to enforce coordination." Presentation, Tim Pozar, A Sample Wireless Broadband Deployment-City of San Francisco Housing Projects, at slide 26 (Apr. 4, 2008), http://www.iep.gmu.edu/documents/GMU-Pozar-20080404.pdf. Pozar provides a useful basic description of unlicensed usage:

As 802.11 [Wi-Fi] is designed for short-range use, such as in offices and homes, it is limited to very low power. Ideally, a well-engineered path will have just the amount of power required to get from point ' $A$ ' to point ' $B$ ' with good reliability. Good engineering will limit the signal to only the area being served, which both reduces interference and provides a more efficient use of the spectrum. Using too much power would cover more area than is needed, and also has the potential to wreak havoc on other users of the band.

Pozar, supra note 244, at 3. More generally, Jon Peha writes:

It has been shown that devices in unlicensed spectrum are likely to transmit for greater duration and at greater power than is necessary, as this will advance other design goals. This phenomenon must be addressed if spectrum is to be used efficiently. The alternative is to allocate excessive spectrum so that contention is rare.

Jon M. Peha, Wireless Communications and Coexistence for Smart Environments, 7 IEEE PERS. COMM., Oct. 2000, at 66, 66.

250. See Workshop Paper, Jon M. Peha, Emerging Technology and Spectrum Policy Reform 5 (Int'l Telecomms. Union Workshop on Market Mechanisms for Spectrum Management, Jan. 2007), http://citeseerx.ist.psu.edu/viewdoc/download?doi=10.1.1.160. $543 \&$ rep $=$ rep $1 \&$ type $=$ pdf ("When releasing unlicensed spectrum, regulators must guard against two related sources of inefficiency. One is that unlicensed spectrum will attract applications that would operate more effectively and efficiently in licensed spectrum. The other is that engineers will design 'greedy' devices, i.e. those that transmit with greater power, duration, or bandwidth than necessary, because they have little incentive to conserve spectrum that is shared. In the extreme, greedy devices can lead to a tragedy of the commons, where many devices are greedy, and all devices in the band experience inadequate performance as a result.") (footnote omitted).

251. Hyun Jin Kim \& Jon M. Peha, Detecting Selfish Behavior in a Cooperative Commons, IEEE DYSPAN, 1 (2008), available at http://ieeexplore.ieee.org/stamp/stamp.jsp?tp= \&arnumber $=4658233$.

252. Ad hoc mesh networks that create "cooperation gain" in unlicensed bands are touted as mechanisms for expanding the capacity of radios using non-exclusive spectrum 
The contrast with liberal licensed bands could not be sharper. Private spectrum owners will internalize the cost of spillovers-emissions that conflict with rival wireless users-and invest heavily to reduce them. Such entities have a readily available efficiency metric to guide this calculus: undertake only those interference-reducing outlays where expected benefits exceed expected costs.

To be rude and to chew up bandwidth on such networks is to pay extra. Pricing schedules steer subscribers towards reducing costly interference, charging higher rates (or, equivalently, limited bucket minutes) for peak time calls. But network efforts to conserve spectrum go much further. Dynamic power control features in cellular phones provide one example of how private networks seek to reduce emissions, making their exclusively controlled bandwidth quieter, expanding valuable opportunities. Courteous protocols, often put forth as a way to share unlicensed spectrum, ${ }^{253}$ are actually hardwired into mobile handsets accessing licensed spectrum. Thus, handsets are developed and programmed to be polite emitters, and manufacturers- to sell to carriers, or be certified to access their spectrum in sales directly to end users - continually press to increase performance at lower power levels, reducing demands on shared frequencies. As Charles Jackson has written, "handsets are part of the network," 254 and carriers are careful to protect their spectrum by promoting (and often subsidizing) radios that behave in friendly fashion.

\section{Smart Radios, Dumb Crowds}

As noted in Section VII.A.1, supra, interference is determined by the total electromagnetic din created by the sum total of all the radios trying to transmit in a band, together with other incidental and inadvertent sources of

rights. But the costs of organizing such solutions are relatively high, which is why the model has yet to be embraced in any appreciable volume. Indeed, the need for network coordination is itself hampered by the lack of spectrum ownership. This is why Jon Peha recommends licensed spectrum to effect the ad hoc mesh solution: "[A] 'spectrum commons' could be created by a license-holder instead of the regulator. Rather than using unlicensed spectrum, a private entity might obtain a license, establish its own operating rules, and allow devices to operate in its spectrum. The latter approach is particularly appropriate for a cooperative system," such as ad hoc meshes. Peha, supra note 250, at 7 (footnote omitted).

253. LAWRENCE LESSig, CODE AND Other LAWS OF CyBERSPACE 184 (1999).

254. Charles L. Jackson, Wireless Handsets Are Part of the Network (Apr. 27, 2007) (filed as Attachment $C$ to Opposition of CTIA-The Wireless Association, Skype Communications S.A.R.L: Petition to Confirm a Consumer's Right to Use Internet Communications Software and Attach Devices to Wireless Networks, RM-11361 (Fed. Commc'ns Comm'n Apr. 30, 2007)), available at http://files.ctia.org/pdf/filings/ Skype_Opposition_Final_Attachments_04302007.pdf. 
noise. In the total-din calculus, the number of radios is important, as is their power. But no one directly controls the total number of transmitters in an unlicensed band.

End users compound the problem when they hang on to obsolete transmitters long after more spectrum-efficient technologies have been developed. Countless radios that rank as "low-power" and "smart" today may still be transmitting with impunity in unlicensed bands ten years hence, occupying spectrum that could be used much more efficiently by much smarter, lower-power technology developed in the interim. Arguments for more unlicensed bandwidth assert that competition between technology suppliers will produce devices that effectively limit interference. This fails to engage the central problem posed by unlicensed wireless users whose economic interest is to keep operating their old radios no matter the spillovers they cause.

Exclusive airwave rights help address both problems. The licensee controls the total number of transmitters (base stations, handsets, M2M radios, ${ }^{255}$ and so forth). It can (and does) hardwire cooperation into such devices, promoting spectrum-saving devices. It also orchestrates orderly transitions from old technology to new. The cellular networks of the early 1980s, for example, were analog by FCC mandate. After the FCC authorized digital upgrades, carriers effected a seamless transition, in part by giving their customers new, less polluting, subsidized phones. ${ }^{256}$

Wi-Fi standards, commons advocates claim, have dealt with the problem of "orphan" technology much better than broadcasters have managed to make the transition from analog to digital television. ${ }^{257}$ This evinces the confusion discussed earlier over the distinction between traditional licenses and liberal licenses. Coordination problems plague the TV market precisely because TV broadcasters do not own their spectrum, cannot transact to rearrange it, and cannot control the radio receivers using it. TV sets are, in other words, unlicensed devices. These receivers are made to government specifications, and the program content they access is transmitted via government mandates.

255. Machine-to-machine wireless devices are a burgeoning part of the mobile network landscape. See Mayo \& Wallsten, supra note 75, at 65-67.

256. The providers had an economic incentive to retain existing customers. For the rules governing the transition, see Year 2000 Biennial Regulatory Review-Amendment of Part 22 of the Commission's Rules to Modify or Eliminate Outdated Rules Affecting the Cellular Radiotelephone Service and Other Commercial Mobile Radio Services, 16 FCC Rcd. 11,169, IT 18-20 (2001).

257. WERBACH, supra note 17 , at 23-24. 
In the cellular market, with its liberal licenses, networks control their airspace and manage the subscriber interface: the leaps in technology-from the flip phones of ten years ago to the iPhones and broadband datacards of today-are large and continuous. No one seems much concerned about the "digital cellular transition" or the "EV-DO transition," despite the fact that the economic consequences for actual consumers are far more profound, remembering that over ninety percent of TV viewing takes place via cable and satellite, unaffected by the digital TV transition-completed in 2009, and officially twenty-two years in the making. ${ }^{258}$

Perhaps the most popular metaphor for the view that smart radios obviate the utility of a controlled spectrum space is the cocktail party tale. The party venue may fill up and the din of the crowd increases to a dull roar. But the human ear is adroit at focusing on just one conversation in the mix. Sometimes so adroit that one can eavesdrop on particularly juicy chatter being conducted halfway across the room. ${ }^{259}$ The moral of the tale is that good receivers can beat a noisy roar. And science has provided just the technologies to make those good receivers.

The cocktail party metaphor popped up long ago in the classroom of Claude Shannon, author of Shannon's Law and a towering figure in modern radio frequency engineering. ${ }^{260} \mathrm{His}$ vision inspired his M.I.T. student, Irwin Jacobs, to implement the insight. Jacobs, with fellow scientist Andrew Viterbi, developed the "spread spectrum" technology that unraveled so many garbled sounds into intelligible conversations and then applied that technology to mass communications. The company they founded, Qualcomm, pioneered advanced wireless networks based not on unlicensed, but licensed, spectrum. ${ }^{261}$ Hence, even the iconic spectrum-sharing technological twist is nested in a globally successful application using

258. The FCC's Advanced Television proceeding actually launched in 1987. See Hazlett, Transition to Yesterday, supra note 19.

259. See On the Same Wavelength, ECONOMIST, Aug. 14, 2004 ("A well-attended cocktail party has a din of many voices speaking at once and on similar frequencies. But it is still possible for party-goers to have conversations and pick out individual voices-ie, sound waves - from the din, because our brains are equipped with powerful software for this task. There is no limitation in the spectrum of sound waves, only in the refinement of the human ear. The same can be true in the electromagnetic spectrum.").

260. See DAVE MOCK, THE QuALCOMM EQUATION 70-72 (2005).

261. U.S. wireless carriers Sprint and Verizon use Qualcomm's CDMA technology. More generally, all $3 G$ technologies are built around CDMA algorithms. "In order for a mobile phone to function on a CDMA-based network (which includes all $3 G$ networks), handset makers must pay royalties to Qualcomm." Brian Colello, CPA, Qualcomm, Inc., MORNINGSTAR, http://quicktake.morningstar.com/s/stock/analysis.aspx?t=QCOM (last visited Apr. 24, 2011). 
exclusive spectrum rights which, among other things, allowed spread spectrum methods to work by limiting the number of conversations and the overall level of noise-necessary for successful communications even with the most advanced science. ${ }^{262}$

\section{Pbysical Separation}

When an antenna transmits equally in all directions, the power of the signal falls with the square of the distance. Obstacles-buildings, trees, and the air itself-cause additional attenuation. The earth's curvature blocks signals from transmitters situated over the horizon. But here too, physical separation involves trade-offs and judgment calls based on the cost and quality of the transmitters and receivers. The ability to squeeze more radios within a given space is at the heart of advanced communications. "Father of the Cellphone," Martin Cooper, estimates that it accounts for the lion's share of a one-million-fold increase in spectrum capacity every fifty years, a relationship now known as Cooper's Law. ${ }^{263}$

With broadcasting, the FCC's historical policy was wide physical spacing to accommodate cheap receivers. ${ }^{264}$ This approach devoted most channels to "taboo" fillers, guard bands left idle to absorb stray interference. As technology improved, the Commission-with long lags-has required less

262. Mock explains:

At the code-division party ... more people are allowed to flood into any one space at the same time to hold discussions. At this party, though, each pair speaks in a different language.... Because you would be keying in on the nuances of your partner's spoken language, all the other languages would just sound like gibberish in the background. Even though thousands of dialects were available for couples to speak, there was still a limit on how many could be spoken at the same time-basically the limit that resulted from the overall noise. If there were fifty couples, all talking different languages, it could get too noisy for anyone to hear. So at the CDMA party it was important to regulate how loudly everyone spoke, to make sure that the maximum number of couples could be heard.

MOCK, supra note 260 , at 71.

263. Martin Cooper, Intermet: $A$ Life Changing Experience, IEEE MULTIMEDIA, Apr-June 2001 , at $11,14$.

264. See, e.g., FCC Notice, $900 \mathrm{MHz}$ and $3 \mathrm{GHz}$ supra note 61, \$T 9, 10 (2002) (describing Commission rule requiring distance separations between channel-adjacent frequencies); J. Walker, Don't Touch That Dial: Free Radio Berkeley Takes on the FCC and Official History, REASON, Oct. 1995, at 30 (quoting San Francisco radio station KQED engineering supervisor Fred Crock as stating that the shortcomings of inexpensive receiver design may have been basis of U.S. broadcast allocations). 
spacing. ${ }^{265}$ The stultification associated with rigid administrative controls is evident. In 1952, four national commercial TV networks existed-ABC, CBS, DuMont, and NBC. 'This set defined the scope of America's programming choice. By 1984, that number had sunk to three. The elimination of rules blocking cable and satellite TV competition then permitted the number of national and local broadcast networks to skyrocket. $^{266}$ But for a generation, regulation put a stranglehold on competitive progress.

The administrative approach to spectrum resulted in massive underutilization of radio, ${ }^{267}$ television, ${ }^{268}$ and other allocated bands. ${ }^{269}$ What appeared to be a cheap way to assure high-quality reception, turned out to be anything but. The opportunity costs - what valuable wireless stuff could have used the taboo channels-have easily dominated any improvement in off-air viewing they provide.

With flexible-use licenses for mobile services, the Commission has abandoned "site licensing" for "geographic licensing." The new approach delegates physical-spacing decisions to wireless operators. The core engineering concept behind "cellular" phone service is that the same frequencies can be reused again and again when arrays of potentially conflicting transmitters are suitably deployed. Wireless carriers are in charge of making these architectural calls. They generally add new cells as they add new subscribers. Wireless carriers thus control the spacing of their emissions. $^{270}$ Neither the FCC nor the licensees can easily control the location of the peripatetic transmitters in cell phones, PDAs, and netbooks,

265. For example, on average, the minimum separation distance for the same channel in neighboring regions is significantly less for DTV compared to typical analog signals. Compare 47 C.F.R. $\$ 73.610$ (b) (2010) with id. $\$ 73.623(\mathrm{~d})$.

266. See, e.g., W. KIP VisCusi, Joseph E. Harrington, JR. \& JOHN M. Vernon, ECONOMICS OF REGULATION AND ANTITRUST 480-81 (4th ed. 2005).

267. See Thomas W. Hazlett \& Bruno E. Viani, Legislators vs. Regulators: The Case of Low Power FM Radio?, 7 BuS. \& POL., no. 1, art. 1 (2005); Thomas Hazlett, Who Killed Micro Radio?, ZDNet (Apr. 17, 2001, 12:00 AM), http://www.zdnet.com/news/who-killed-micro-radio/ 115396.

268. See Hazlett, U.S. Digital TV Transition, supra note 19.

269. See Thomas W. Hazlett, Optimal Abolition of FCC Spectrum Allocation, 22 J. ECON. PERSP. 103, 109 tbl.2 (2008).

270. See 47 C.F.R. $\$ 22.907$ (2010) ("Licensees in the Cellular Radiotelephone Service must coordinate, with the appropriate parties, channel usage at each transmitter location within [ 75 miles] of any transmitter locations authorized to other licensees or proposed by tentative selectees or other applicants, except those with mutually exclusive applications."); id. $\$ 24.134$ ("A co-channel separation distance is not required for the base stations of the same licensee or when the affected parties have agreed to other co-channel separation distances."). 
so carriers follow their customers, building out facilities, splitting cells to increase capacity, executing roaming agreements for seamless "out of market" service, and pricing calls to limit crowding. ${ }^{271}$

Recently, carriers have followed their customers all the way to their homes, offering to better extend the reach of their WANs. T-Mobile offers a device that routes in-home calls to broadband modems (connected to DSL, fiber, or cable data networks) for VolP connections using Wi-Fi links, with calls flipping over to mobile networks when the subscriber hops in her car and drives off. ${ }^{272}$ Alternatively, carriers supply subscribers with "femtocells," miniature base stations that extend "four bars" to the individual subscriber's home. ${ }^{273}$ These transceivers may utilize the carrier's licensed frequencies within the home, but then route outgoing traffic via (fixed) broadband links. ${ }^{274}$

Advanced wireless technologies are alleged to put the role of geographical separation in network planning to an end. Radios in close proximity are now easily coordinated by smart technologies that use simple etiquettes to coordinate emissions. Mesh networks use Wi-Fi radios as links in a chain over which they hop across the Internet, creating capacity with the additional user. Instead of limiting capacity, the more the merrier: extra radios will mean more coverage, and more total wireless capacity, too. ${ }^{275}$ Where scarcity and conflicts once reigned, abundance now flowers. ${ }^{276}$

271. There is no irony in the fact that most customer minutes are "free," in the sense of being off-peak, on-net, or within the allotted "bucket." So long as network "members" support the jointly shared facilities (including spectrum) with monthly subscription fees, the carrier enthusiastically extends access rights (which, of course, is why subscribers join). Metering peak minutes that run past the bucket limits congestion.

272. Andrew Berg, T-Mobile Intros Wi-Fi Plan for Enterprise, WIRELEsS WEEK (May 7, 2009), http://www.wirelessweek.com/News-T-Mobile-Wi-Fi-Plan-Enterprise-050709.aspx.

273. Derek Kerton, Pre-Brief of the Upcoming CTLA Conference, TECHDIRT (Mar. 31, 2009, 2:59 AM), http://www.techdirt.com/articles/20090330/2030174313.shtml.

274. Glenn Fleishman, Verizon Getting on Femtocell Bandwagon with Sprint, AT\&-T, ARS TECHNICA (Jan. 19, 2009, 1:20 PM), http://arstechnica.com/telecom/news/2009/01/ verizon-getting-on-femtocell-bandwagon-with-sprint-att.ars.

275. Benkler, supra note 17 , at 45 ("[A]dding users with the right kind of equipment to an open wireless network can add capacity, not only demand.").

276. Gregory Staple \& Kevin Werbach, The End of Spectrum Scarcity, IEEE SPECTRUM (Mar. 2004), http://www.spectrum.ieee.org/mar04/3811/ (" $[E]$ very new device uses some of the network's capacity but also adds capacity back. Because a device in a mesh no longer needs to send information all the way to its ultimate destination (such as a cell tower), it can use less power. That allows the network to add more devices without any noticeable increase in interference."). 
But wireless meshes, which have been available for over a quarter century, ${ }^{277}$ are no free radio spectrum lunch. Costs of coordinating the mesh are substantial—so high, relative to the alternatives, that ad hoc meshes are virtually non-existent. Some agencies, including the U.S. military, do use mesh networks, but these are engineered top-down, not spontaneously, and the network providers that create such systems could purchase spectrum inputs just as mobile carriers do. Indeed, mesh networks are built using licensed spectrum. ${ }^{278}$ The promise of meshes as disruptive innovations was that they would eliminate the network coordination function altogether. ${ }^{279}$ That promise has not been realized. ${ }^{280}$ ArrayComm, a wireless technology firm pioneering the development of "smart antennas," offers a general explanation:

The final and most confused argument against concerns about spectrum availability rests on the belief that "technology" will solve the problem by enabling through cognitive radios and other concepts the peaceful cohabitation of spectrum by formerly interfering applications. While there are large tracts of allocated but currently underutilized spectrum in the mobile-device sweet spot, especially for public safety and military applications, and while it is true in principle that continuing advances in signal processing technologies will eventually make the collaborating-radios vision feasible, the predominant view is that the long timeline for its realization does not make this argument relevant for current business planning purposes. In the meantime, the industry must

277. Kristin Masters, Mesh Networks, POWERSOURCE ONLINE (Mar. 2010), http://www.powersourceonline.com/magazine/2010/03/mesh-networks; see also, e.g., D. J. Baker, J. Wieselthier \& A. Ephremides, A Distributed Algorithm for Scheduling the Activation of Links in a Self-Organizing, Mobile, Radio Network, in 1 IEEE 1982 INTERNATIONAL COMMUNiCATIONS CONFERENCE, at 2F.6.1 (1982); N.F. Maxemchuk, Regular Mesh Topologies in Local and Metropolitan Area Networks, 64 AT\&T TECH. J. 1659 (1985). See generally Tim B. Lee, Multi-Hop Matters: The State of Wireless Mesh Networking, ARS TECHNICA (Dec. 1, 2009), http://arstechnica.com/tech-policy/news/2009/12/mesh-networks-come-of-age.ars.

278. The $4.9 \mathrm{MHz}$ band, allocated for licensed use by public safety organizations, hosts significant mesh deployments. See FARPOINT GRP., INTERFERENCE AND METRO-SCALE WIFI MESH NETwORKS 4 (Jan. 2008), available at http://www.ict-partner.net/en/US/ solutions/collateral/ns340/ns394/ns348/ns736/net_implementation_white_paper0900aecd 805eb886.pdf.

279. Benkler, supra note 17 , at 47.

280. R. P. Karrer, A. Pescapé \& T. Huehn, Challenges in Second-Generation Wireless Mesh Networks, 2008 EURASIP J. WIRELESS COMM. \& NETWORKING (Aug. 2008), available at http://www.hindawi.com/journals/wcn/2008/274790.html ("[T] he performance of the [mesh] networks is dismal; experience shows that the throughput is limited, and unfairness and throughput degradations of multihop communication impose severe limitations. Moreover, from an economical perspective, subscription rates to city-wide meshes, such as in San Francisco, are dismal.") (footnote omitted). 
maintain its focus on more efficient policies for licensed spectrum use ... 281

Tellingly, what have been deployed are network-centric meshes, where a carrier distributes devices across an area, hardwires them to coordinate their use, and then links them to a broadband connection (over privately owned spectrum) to the Internet. This mimics the structural model of the cellular operator.

One difference, of course, is found in performance. Whereas mesh networks are designed for limited applications and have great difficulty handling mobile communications, cellular networks provide ubiquitous mobile coverage and scale to handle billions of minutes of use. The market test has been run. Were wireless meshes to render spectrum scarcity moot, the unlicensed bands would have displaced the cellular bands and the $\$ 160$ billion per year mobile industry would have been displaced by mesh carriers using "free" airwaves.

\section{B. TECHNOLOGICAL INNOVATION AND MARKET EFFICIENCY}

When it liberally licenses spectrum, the FCC largely deregulates hardware. When it unlicenses spectrum, the FCC necessarily regulates hardware.

In the CMRS bands, where spectrum is licensed for flexible use, the licensee has wide discretion to decide what mix of low-power and highpower radios to deploy, selecting a mix to maximize profits. When spectrum is unlicensed, the regulator must-and does-regulate radio hardware power and standards. "Low-power," "smart," and "non-interfering threshold" are not technical terms, but regulatory constructs.

Thus, however smart they may be, all "intentional radiators" are regulated under Part 15, Subpart C, of the FCC rules, the first section of which establishes an "equipment authorization requirement." This Subpart goes on to regulate antennas, power amplifiers, and bands of operation, and then it sets out detailed "radiated emission" limits, band by band. ${ }^{283}$ The radios used in licensed bands require FCC approval, too. But Part 15 regulation of devices that operate in unlicensed bands is much more intrusive

281. Marketing Materials, ArrayComm, Wireless Isn't Broadband Without Us: Navigating the Harsh Realities of Broadband Wireless Network Economics 9 (2004), http://www.arraycomm.com/docs/ArrayCommonMBWAecons.pdf (footnote omitted).

282. This is true for every other developed country, as well. The "open access" free-forall that is sometimes advanced as a regulatory alternative is simply utopian. The only country reported not to regulate unlicensed radio devices is Haiti, but little use is made of the policy. Jon M. Peha, Lessons from Haiti's Internet Development, 42 CoMM. ACM, no. 6, June 1999, at 67, 71 (1999).

283. See 47 C.F.R. $\ 15.201(2010)$. 
because it strictly regulates power, one of the two most important technical characteristics (alongside operating frequency) of every radio.

There is no law of engineering that says everyone will always be better served by low-power, short-range radios. Transmitting from 23,000 miles in space and covering half the continent, direct broadcast satellites deliver competitive digital television signals to over one hundred million households, including those in rural communities that have no prospect of getting comparable video service from unlicensed wireless devices any time soon. Mobile carriers built out their networks efficiently by starting with fewer, larger, higher-power cell sites; more cell sites and lower power radios followed in step with growth in subscribers and minutes of use. Here too, the economical roll-out of service in rural areas has often depended on using taller masts and higher-power transmitters to provide large service footprints across thinly populated areas. Where people are sparse, simpler, cheaper radios that "waste" spectrum are more efficient, because there is spectrum to spare. $^{284}$

These are exactly the tradeoffs that liberal license holders routinely discover and efficiently exploit. The FCC's settled policy is now to give licensees "flexibility to determine the types of services and the technologies and technical implementation designs used to provide those services." 285 Technology choices have thus emerged as a key dimension of competition among service providers.

Because about half of all transmissions originate in the hands of end users, ${ }^{286}$ wireless carriers have also invested heavily to get high-performance, feature-rich, spectrum-efficient wireless devices into their customers' hands. Carriers paid about three-quarters of the approximately $\$ 14$ billion spent on mobile phones in the United States in $2003{ }^{287}$ Such subsidies reflect carriers' propertied interest in their spectrum. Newer phones embed more advanced technologies, reducing spectrum spillovers (interference) and offering greater functionality for users. Both are of value to the network over and above the gains delivered to the individual adopter. Hence, handset subsidies are higher for newer models and have been particularly important in spreading $3 G$

284. Ellen P. Goodman, Spectrum Rights in the Telecosm To Come, 41 SAN DIEGO L. REV. 269, 308-09 (2004).

285. Interference Temperature Metric, 18 FCC Rcd. 25,309, ๆ 6 (2003).

286. See Jackson, supra note 254.

287. Mike Dano, Phone Subsidies Alive and Well, RCR WIRELESS NEWs, Jan. 5, 2004, at 1. 
technology. ${ }^{288}$ Many smaller networks have more aggressively supplied subsidies, underscoring the competitive role of such vertical promotions. ${ }^{289}$

Unlicensed bands accommodate non-exclusive use rights but require highly exclusionary public policies. The technologies authorized in unlicensed bands effectively prohibit most wireless options, on the expectation that they would cause harmful interference. When the FCC unlicenses spectrum, carriers and consumers must choose Intel's Centrino chips over Qualcomm's CDMA chips and Wi-Fi access points over data networks provided by GSM UMTS/HSDPA, CDMA 1xEV-DV, or WiMax optimized for licensed radio spectrum. ${ }^{290}$

The fact that the approved low-power technology choices sometimes result in widespread adoption is evidence that not all social value is eliminated by the allocation policy. It does not, however, prove that the resulting wireless activity is the optimum. A government-managed band does not contain the requisite feedback mechanisms to reveal and then adjust to the most efficient spectrum sharing arrangements. It is always possible that an alternative set of rules would generate greater gains. But whereas owners of licensed spectrum have profit incentives and the financial ability (i.e., access to capital markets) to arrangc positive-sum transactions to make such transitions as present themselves as good candidates for superior results, spectrum regulators do not.

Some unlicensed bands appear to have performed well, like the $900 \mathrm{MHz}$ and $2.4 \mathrm{GHz}$ bands, while others, like U-PCS and the $3650 \mathrm{MHz}$ band, appear to constitute allocation failures. But regulators have no reliable way to optimize any particular band because the relevant counter-factual obviously cannot be observed. More basically, even after the fact-when the FCC observes "tremendous success" or some other categorically salubrious outcome-it is under no pressure to perform the relevant social welfare calculation: was the FCC's allocation, and the associated rules (including adoption of the unlicensed access model and the restrictions on radio usage

288. See Marko Repo, Regulation of Wireless Stakeholders 4 (Seminar on Networking Business, Helsinki Univ. of Tech., Paper, Oct. 2006), http://www.netlab.tkk.fi/opetus/ s383042/2006/papers_pdf/B2.pdf; Ville Saarikoski, The Odyssey of the Mobile Internet 7 (2006) (unpublished Ph.D. thesis, University of Oulo, Finland).

289. See Pedro Pita Barros, Handset Subsidies-An Empirical Investigation 3 (Aug. 14, 2008) (unpublished manuscript), available at http://www.anacom.pt/streaming/est22112006. pdf? categoryId $=218502 \&$ contentId $=424227 \&$ field $=$ ATTACHED_FILE.

290. This set of technologies appears to include WiMax, by many accounts the most advanced technology thus far emerging from the Wi-Fi family. Wi-Fi? How About Way Far? WiMax Delivers High-Speed Wireless Intemet Service as Far as 35 Miles Away, HARTFORD COURANT, Mar. 25, 2004, at D3. 
attendant to that approach), the most efficient way to use this particular bandwidth? Could markets have supplied more creative, lower-cost ways to accommodate the services obtained, while stimulating additional wireless services of value to consumers? That the FCC does not have the institutional ability to make such judgments with the reliability of alternative institutions, notably profit-maximizing capital owners in competitive markets, is obvious. Perhaps most striking is that the FCC does not even, as a pro forma matter, deem it necessary to ask the question.

Government employees are constrained to be disinterested. They do not generate information as to profitable opportunities for spectrum re-use but, rather, maximize utility under the political realities governing their agency. Whereas entrepreneurs scour the marketplace looking for assets that are undervalued, searching for the financial means to divert such resources to more productive employments, the bureaucratic goal is to preserve an existing governing equilibrium.

It is unknowable within an administrative allocation system whether a given unlicensed block-even where it is certifiably creating more benefit than cost in aggregate-is of the right size. Perhaps the $2.4 \mathrm{GHz}$ ISM band would optimally be half, or twice, its present scope. Without ownership, there are no transactions, and without transactions, no market values. This leaves regulators guessing about where to draw lines.

Suppose that a firm like Apple, instead of arguing for the government to allocate more bandwidth to license-exempt use, were to buy liberal licenses and then provide a "spectrum commons" on its own. ${ }^{291}$ It could then set frequency sharing rules, including technology formats and power limits, becoming a private FCC. In fact, this is the vertical structure of the mobile carrier space that already exists, the twist being a business model that rides by contract on the carrier's network infrastructure and yet "opens" the licensed airwaves to radio devices and applications provided by hundreds of third party providers.

Under this approach, competitive market forces regulate the performance of Apple in providing the "commons." Just as carriers are rewarded for providing customers with superior user experiences, the "unlicensed" space would become profitable to the degree that sharing rules were properly balanced. Not only is such a model already well established, if not ubiquitous,

291. This option has been suggested by many analysts, including professional staff at the FCC. See Kwerel \& Williams, supra note 8, at 31. 
in the licensing of intellectual property rights, ${ }^{292}$ it mirrors the system in place for mobile carriers. There, device makers contract to gain access to carriers' networks and spectrum assets, passing the rights to customers who "play" their radios right out of the box. Mobile handsets, including those like TracFone (a virtual mobile operator that enables wireless phone calls using access rights purchased in wholesale markets) or Kindle (a book reader, sold by Amazon, that downloads content via Amazon's contract with Sprint) embed seamless spectrum access rights for end users.

The advantages of such an approach over administrative allocation are manifest. But such an outcome is displaced by mandated allocations to unlicensed allocations. Hence, public policy drove Apple to request that the government place spectrum resources at risk, inviting its lobbyists to steer allocations rules in the direction sought by the firm-no payment required. Whatever Apple has gained from unlicensed band set asides, the regulatory process has muddled transparency, undermined productive efficiencies, and blocked information-rich feedback loops. It should be noted, of course, that Apple has since emerged as a powerhouse in the wireless sector by abandoning its quest for unlicensed allocations in favor of contracts with carriers owning exclusive spectrum rights. ${ }^{293}$

\section{CONCLUSION}

Administrative allocation of radio spectrum has historically been plagued by overly conservative policies that unduly limited competition and blocked technological innovation. But as broadcasting was eclipsed by mobile telephony, a subtle shift in policy took hold that in hindsight amounted to a policy revolution. In the modern marketplace, liberal spectrum licenses host extremely complex economic structures, allowing millions of customers to buy wireless services using advanced technologies, while facing a continually increasing number of access options and applications. This regime generates intense sharing of spectrum by rival networks and by mass-market

292. This analogy is nicely developed in WILLIAM J. BAUMOL \& DOROTHY ROBYN, TOWARD AN EVOLUTIONARY REGIME FOR SPECTRUM GOVERNANCE: LICENSING OR UNRESTRICTED ENTRY? (2006).

293. Apple's lobbying for U-PCS in the 1990s was driven by a strategy to secure wireless access for its early PDA, the Newton. That the Newton flopped may or may not be associated with the limitations of the regulatory process generally, or the U-PCS allocation specifically. That the iPhone's success following its 2007 launch is associated with liberal licenses and the wide area networks they enable is, however, crystal clear. No other spectrum regime could provide the level of social organization necessary to accommodate the access services embedded in the iPhone. 
subscribers to voice and data services. In delegating choices to competitive firms, de facto airwave ownership rationalizes spectrum use.

The suggestion that exclusive rights to radio spectrum are made obsolete by advancing technology has the basic economic coordination problem backwards. The advanced wireless devices are today superior, in their ability to send and receive data, to previous generations. But they cannot be fruitfully deployed without some form of social control over the airwaves they access. The alternative to competitive ownership is the imposition of behavioral constraints by regulators. Power limits and technology restrictions are inevitably applied to license-exempt spectrum to limit conflicts. Smart radios do not portend the "end of scarcity" but constitute yet another ascending pathway on the mountain wireless entrepreneurs have been climbing since Marconi blazed a trail for wireless innovations in 1895.

That seminal technological breakthrough triggered a chain of events that created spectrum scarcity. Contrary to the view that advanced devices solve such mundane matters of economic organization and obviate the value of exclusive spectrum rights, each new and improved radio actually triggers more demand for airwave access, increasing potential spectrum conflicts. Intensifying calls for more unlicensed spectrum in more desirable bands reflects just this scarcity, with rival claims made in the political marketplace. The pro-consumer policy unleashing the social value of wireless would shift such competitive bidding from the political marketplace to the economic realm.

This approach carries great promise and little risk. There is nothing that "spectrum inventories" held by government can achieve. The most reliable way to destroy valuable spectrum, in fact, is not to use it. The second most reliable way is to distribute a massive number of tiny, overlapping rights that cannot be usefully re-aggregated-the Humpty Dumpty approach that can easily result from unlicensed allocations. ${ }^{294}$ By allocating liberal licenses to competitors, however, market forces will divert spectrum resources to where demands are highest. If regulators in the future ascertain that important demands are unmet, it will be free to acquire frequencies for the task and to know the market price of doing so.

The $700 \mathrm{MHz}$ licenses auctioned in March 2008 raised $\$ 19$ billion for the U.S. Treasury. Those bids reflect future anticipated profits (now transferred to the government) available to firms that control the resource rights

294. On tragedy of the anti-commons generally, see HELLER, supra note 138 . On such tragedy with respect to unlicensed use of television band "white spaces," see Thomas W. Hazlett, Tragedy T.V.: Rights Fragmentation and the Junk Band Problem, 53 ARIZ. L. REV. 83 (2011). 
conveyed. Nothing prevented bidders from purchasing such bandwidth and deploying it as a "spectrum commons"; indeed, that approach would seem an attractive alternative to spending the many billions of dollars on network infrastructure required in executing the mobile carriers' network-centric model-were customers willing to pay for the services therein offered.

Marketplace rejection of the "commons" model does not constitute market failure, but a competitive equilibrium. It reveals that there are superior choices, given the available technologies and the associated consumer demands, for using valuable radio frequencies. That is the rationality supplied by liberal spectrum licenses. 
